\title{
VOM MARGINALEN GRENZRAUM ZUM KERNRAUM EUROPAS. DAS RÖMISCHE HEER ALS MOTOR DER NEUSTRUKTURIERUNG HISTORISCHER LANDSCHAFTEN UND WIRTSCHAFTSRÄUME
}

\author{
KARL STROBEL
}

Ein zentrales Phänomen in der Geschichte der römischen Provinzen in der Frühen und Hohen Kaiserzeit ${ }^{1}$ ist die demographische, siedlungsmäßige und wirtschaftliche Neustrukturierung großer Räume Europas, deren Bedeutung vielfach die mittelalterliche und neuzeitliche Entwicklung prägte und bis in die Gegenwart wirksam ist. Klassische Beispiele hierfür sind die Rheinlande, Britannien oder die Zone zwischen Alpen und Donau. In anderen Zonen wie dem mittleren und unteren Donauraum und in Dakien war die Neustrukturierung ebenso massiv, war dann aber oftmals großen Kontinuitätsbrüchen unterworfen. Gleiches gilt für Nordafrika.

Der Naturraum wie der historische Raum bilden einerseits die vorgegebenen Größen, in denen sich historisches Handeln und geschichtliche Entwicklungen abspielen, doch sind beide Größen zugleich dem Wandel durch historische Prozesse unterworfen. Selbstverständlich sind die grundsätzlichen Voraussetzungen des Naturraumes vom Menschen nicht veränderbar, doch können auch sie durch infrastrukturelle Maßnahmen wie Straßenbau oder Amelioration, aber auch durch Eingriffe in das ökologische Gleichgewicht verändert werden. Die wohl charakteristischsten Phänomene sind die Umwandlung in Kulturland im Rahmen der agrarischen Wirtschaftsformen mit ihren Auswirkungen auf Flora und Fauna bzw. die Rodung von Waldgebieten und der Aufbau von Siedlungsnetzen. ${ }^{2}$ Dabei kann der Raum Phasen

${ }^{1}$ Ein Resümee jetzt in C. Lepelley (Hg.), Rom und das Reich in der Hohen Kaiserzeit 44 v. Chr-260 n. Chr. II. Die Regionen des Reiches (München - Leipzig 2001).

${ }_{2}$ Vgl. etwa H. Bender und H. Wolff, Hgg., Ländliche Besiedlung und Landwirtschaft in den Rhein-Donau-Provinzen des Römischen Reiches, 2 Bde. (Espelkamp 1994); W. Dörfler, A. Evans, U. Nakoinz, H. Usinger, und A. Wolf, ,Wandel der Kulturlandschaft als Ausdruck des kulturellen Wandels?', in A. Haffner - S. von Schnurbein, Hgg., Kelten, Germanen, Römer im Mittelgebirgsraum zwischen Luxemburg und Thüringen (Bonn 2000), 129-146; beispielhaft H. Kroll, ,Zum Ackerbau in Wallendorf in vorrömischer und römischer Zeit', ebd. 
grundlegender Neustrukturierung durchlaufen, das heißt als eine neu geformte Größe konstituiert werden, die dann die Voraussetzung für die weiteren historischen Entwicklungen erst schafft. ${ }^{3}$ Ein solcher Prozess kann dabei sehr wohl auf primär politische Entscheidungen zurückgehen, deren langfristige Folgen in dieser Weise gar nicht intendiert gewesen sind oder aber gar nicht absehbar waren. ${ }^{4}$ Derartige Phasen grundlegender Neustrukturierung sind keineswegs auf das Zeitalter der Industrialisierung oder auf das 20. Jahrhundert beschränkt gewesen. Gerade das Imperium Romanum in der frühen Kaiserzeit gibt dafür ein eindrucksvolles Beispiel. Man könnte dies auch in Kleinasien nachvollziehen, oder für das 1.-2. Jh. n. Chr. im Balkanraum, doch soll hier das Augenmerk auf das östliche Gallien und insbesondere auf den Raum zwischen Maas und Rhein, gelegt werden. ${ }^{5}$ Politisches

122-128; A. Kreuz, ,Landwirtschaft im Umbruch? Archäobotanische Untersuchungen zu den Jahrhunderten um Christi Geburt in Hessen und Mainfranken', Berichte der Römisch-Germanischen Kommission 85 (2004), 97-292; auch F. Malrain, V. Matterne und P. Méniel, Les paysans gaulois. III siècle-52 av. 7.C. (Paris 2002); V. Matterne, Agriculture et alimentation végétale durant l'âge du Fer et l'époque gallo-romaine en France septentrionale (Montagnac 2000).

${ }^{3}$ Vgl. etwa R. Frei-Stolba, Hg., Siedlung und Verkehr im Römischen Reich. Römerstraßen zur Herrschaftssicherung und Landschaftsprägung (Bern 2004); F. Burgard und A. Haverkamp, Hgg., Auf den Römerstraßen ins Mittelalter. Beiträge zur Verkehrsgeschichte zwischen Maas und Rhein von der Spätantike bis ins 19. Jahrhundert (Trier 1997).

${ }^{4}$ Vgl. etwa die Beiträge in Zwischen Gallia und Germania, Frankreich und Deutschland. Konstanz und Wandel raumbestimmender Kräfte (Trier 1987), 31ff.; auch zu einer vergleichbaren Problemlage G.-M. Hüssen, W. Irlinger und W. Zanier, Hgg., Spätlatènezeit und frühe römische Kaiserzeit zwischen Alpenrand und Donau (Bonn 2004). Zahlreichen belgischen, niederländischen und deutschen Kollegen danke ich für die Auskünfte über den aktuellen archäologischen Forschungsstand des Jahres 2004, auf dessen Ergebnisse ich hier im Folgenden hinweisen kann.

${ }^{5}$ Vgl. etwa H. Wolff, ,Die politisch-administrative Binnengliederung des gallischgermanischen Raumes', in Zwischen Gallia und Germania 1987, a.a.O. (Anm. 4), 63-82; dens., ,Civitates ohne städtischen Hauptort', in Von Sacerdotium und Regnum. Festschrift E. Boshoff (Köln-Wien-Weimar 2002), 3-10; weiter die Beiträge in G. Gottlieb, Hg., Die Raumordnung im römischen Reich: Zur regionalen Gliederung in den gallischen Provinzen, in Raetien, Noricum und Pannonien (München 1989); G.M. Ternes, Hg., L'évolution des villes entre Rhin et Meuse. BAL 26, 1997 (Luxemburg 1998); allgemein auch N. Hanel und C. Schucany, Hgg., Colonia-Municipium - Vicus (Oxford 1999). Zur Einwirkung auf die Strukturen jenseits der Rheinlinie etwa M. Erdrich, Rom und die Barbaren. Das Verhältnis zwischen dem Imperium Romanum und den germanischen Stämmen vor seiner Nordwestgrenze von der späten Republik bis zum gallischen Sonderreich (Mainz 2001). Zur Entwicklung in Gallien allgemein $\mathrm{R}$. Bedon, Les villes des trois Gaules de César à Néron dans leur contexte historique, territorial et politique (Clemency 1999); G. Precht, Hg., Genese, Struktur und Entwicklung römischer Städte im 1. Fh. n. Chr. in Nieder- und Obergermanien (Mainz 2001); T. Grünewald, Hg., Germania Inferior, Besiedlung, Gesellschaft und Wirtschaft an der Grenze der römisch-germanischen Welt, RGAErg.-Bd. 28 (Berlin-New York 2001); T. Grünewald und S. Seibel, Hgg., Kontinuität und 
Handeln der römischen Reichsführung, das zu einer solchen grundlegenden und langfristigen Neuformierung des Raumes führte, soll im Mittelpunkt dieser Ausführungen stehen. Fragen wir nach dem Motor der Umsetzung entsprechenden Planens und Handelns, so tritt uns das römische Heer als zentrales Instrument der Staatlichkeit des Imperium Romanum der Kaiserzeit entgegen. Doch geht die Wirkung des Heeres noch weit über diesen direkten Aktionsbereich hinaus. Diese Perspektiven des Handelns und der Präsenz des römischen Heeres sollen im Mittelpunkt des Beitrages stehen, wobei sich die Ausführungen aus räumlichen Gründen und mit Rücksicht auf den Beitrag von Gabriele Weiler neben einigen grundsätzlichen Betrachtungen auf die Beispiele Trier, Augusta Treverorum, und Mainz, Mogontiacum, konzentrieren werden. Ersteres zeigt die Etablierung eines neuen Civitas-Zentralortes mit dauerhafter Wirkung auf die Strukturierung des Raumes, letzteres ist das Paradebeispiel für die Entwicklung eines urbanen Zentrums aus der Präsenz des Heeres heraus.

Diesseits des Niederrheins finden wir eine solche völlige Neustrukturierung in der Zone des ehemaligen Eburonengebietes, dessen Stammestruktur von Caesar zerschlagen und dessen Bevölkerungsdichte durch den römischen Vernichtungskrieg stark reduziert worden war. Eine neue historisch-geographische und ethnische Landkarte wurde hier von römischen Seite unter Ansiedlung rechtsrheinischer germanischer Bevölkerungsgruppen, so der Tungrer, Bataver, ${ }^{6}$ Ubier oder Cugerner,

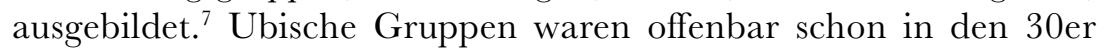

Diskontinuität. Germania Inferior am Beginn und Ende der römischen Herrschaft, RGA-Erg.-Bd. 35 (Berlin - New York 2003).

6 Zur Ansiedlung des chattischen Teilstammes der Bataver wohl bereits im Rahmen caesarischer Politik und Errichtung ihrer besonders privilegierten Civitas wahrscheinlich zu Beginn der 30er Jahre des 1. Jh. v. Chr. vgl. N. Roymans, Ethnic Identity and Imperial Power. The Batavians in the Early Roman Empire (Amsterdam 2004); J. Heinrichs, 'Ubier, Chatten, Bataver. Mittel- und Niederrhein ca. 70-1 v. Chr.', in: Grünewald und Seibel 2003, a.a.O. (Anm. 5), 266-344. S. ferner u. Anm. 10 und S. 230f.

7 Vgl. Roymans 2004, a.a.O. (Anm. 6), 196ff.; Heinrichs 2003, a.a.O. (Anm. 6); R. Wolters, ,Germanische Mobilität und römische Ansiedlungspolitik: Voraussetzungen und Strukturen germanischer Siedlungsbewegungen im römischen Grenzland, in Grünewald 2001, a.a.O. (Anm. 5), 146-168; W. Eck, Köln in römischer Zeit (Köln 2004), $31 \mathrm{ff}$. (unrichtig ist die Gleichsetzung des Dünsberges mit dem Siedlungskern der Ubier, ebenso die Annahme einer römischen Eroberung des Dünsberges), 46ff. Vgl. zu Untergermanien insgesamt die Beiträge in Grünewald 2001, a.a.O. (Anm. 5), bes. H. Van Enckevort, ,Bemerkungen zum Siedlungssystem in den südöstlichen Niederlanden während der vorrömischen Eisenzeit und der Römerzeit', 336-396; Precht 2001, a.a.O. (Anm. 5), bes. H. Galsterer, ,Gemeinden und Städte in Gallien und am 
Jahren des 1. Jh. v. Chr. über den Rhein gekommen; ihre ursprünglichen Siedlungsräume lagen im Neuwieder Becken und um die untere bis mittlere Lahn, ${ }^{8}$ wo allerdings das spätlatènezeitliche Oppidum des Dünsberges die ursprüngliche chattisch-batavische Mittelpunktssiedlung, die etwa eine Generation vor der Errichtung von Waldgirmes verlassen worden war, darstellte. ${ }^{9}$ Die weitgehende Ansiedlung der Ubier auf dem linken Rheinufer durch Agrippa gehört jedoch erst in dessen zweiten Aufenthalt in Gallien 19/18 v. Chr. ${ }^{10}$ Die noch von den Ubiern gehaltenen Gebiete östlich des Rheins im unteren Lahnbereich wurden von Drusus den Chatten gegeben.

Im sogenannten ,freien Germanien' wird die ordnungspolitische Neustrukturierung des Raumes ${ }^{11}$ durch die Gründung eines städtischen Vorortes für den Volksverband der Chatten in Waldgirmes im mittleren Lahntal deutlich. ${ }^{12}$ Die Errichtung dieser nach römischem Muster mit Forum, Basilika und Monumenten des Kaiserkultes im Aufbau befindlichen Stadt, die vermutlich als Oppidum Chattorum bezeichnet wurde, brach im Jahre 9 n. Chr. nach einer Belegungsdauer von etwa 10 Jahren $^{13}$ mit der Varus-Katastrophe und dem römischen Rückzug auf die Basen der linken Rheinseite ab. Wie die jüngsten

Rhein', 1-9. Abzulehnen sind die Thesen von J. Slofstra, 'Batavians and Romans on the Lower Rhine. The romanisation of a frontier area', Archaeological Dialogues 9 (2002), 16-38, 55-57, es seien weder reguläre Civitates eingerichtet noch eine Urbanisierung begonnen worden; vgl. auch Roymans 2004, a.a.O. 197.

${ }^{8}$ Den Ubiern ist sehr wahrscheinlich das 34ha umfassende, überaus stark befestigte Oppidum Dornburg bei Limburg als Zentralsiedlung im Lahnbereich zuzuordnen. Vgl. F.-R. Herrmann, in S. Rieckhoff und J. Biel, Hgg., Die Kelten in Deutschland (Stuttgart 2001), 333-335; F.-R. Herrmann und A. Jackenhövel, Die Vorgeschichte Hessens (Stuttgart 1990), $348 f$.

9 Vgl. Roymans 2004, a.a.O. (Anm. 6), 67ff., 148; zum Dünsberg u. S. $230 f$.

${ }^{10}$ Vgl. K.-H. Dietz, DNP 3 (1997), 72-76; R. Wiegels, DNP 12/1 (2002), 961-962; Eck 2004, a.a.O. (Anm. 7), 46ff.; J. Heinrichs, Civitas Ubiorum. Historisch-numismatische Studien zur Geschichte der Ubier und ihrer Gebiete, Habil.-schr. Köln 1996. Verfehlt ist die Postulierung einer primär ,ubischen' Münzprägung bei Heinrichs und Eck mit Bezug auf die Dünsberg-Prägungen; vgl. Roymans 2004, a.a.O. (Anm. 6). S. ferner o. Anm. 6.7.

${ }^{11}$ Vgl. S. von Schnurbein, Augustus in Germanien. Neue archäologische Forschungen, KroonVoordracht 24 (Amsterdam 2002).

${ }^{12}$ Vgl. zu Waldgirmes A. Becker und G. Rasbach, ,Waldgirmes. Eine augusteische Stadtgründung im Lahntal', Berichte der Römisch-Germanischen Kommission 82 (2001), 591-610; diess., ,Die spätaugusteische Stadtgründung in Lahnau-Waldgirmes', Germania 81 (2003), 147-199; A. Becker, ,Lahnau-Waldgirmes. Eine augusteische Stadtgründung in Hessen', Historia 52 (2003), 337-350; von Schnurbein 2002, a.a.O. (Anm. 11), 5ff.

${ }^{13} \mathrm{Im}$ Forumsbereich sind 4 Bauphasen des Platzes festgestellt worden; vgl. Berichte der Römisch-Germanischen Kommission 82 (2003), 364f. 
Untersuchungen zeigen, setzte sich die Bebauung auch außerhalb der als Holz-Erde-Mauer errichteten Stadtbefestigung fort. Das Baulager der hier eingesetzten Baukolonnen des Heeres konnte ebenfalls außerhalb der Umwehrung festgestellt werden. Auch in Haltern zeichnet sich vor 9 n. Chr. ein Wandel insbesondere im Bereich des sogen. Hauptlagers von einer zentralen militärischen Basis hin zu einem administrativen Zentrum ab. Zugleich entwickelte sich hier eine bedeutende handwerkliche Produktion. ${ }^{14}$ In Anreppen konnte sehr wahrscheinlich die zeitweise Residenz des Tiberius 4-5 n. Chr. erkannt werden; das Lager diente offensichtlich als zeitweilige Statthalterresidenz.

Tacitus spielt einmal kurz auf diese „novae coloniae“, neuen Römerstädte, $a^{15}$ und in Cassius Dio finden wir den lange umstrittenen Locus Classicus für die augusteische Städtegründungspolitik in dem Gebiet östlich des Rheins, dessen Organisation als Provinz spätestens seit 4-5 n. Chr. bereits im Fortschreiten begriffen war: „Ihre Truppen (i.e. der Römer) überwinterten dort und es wurde mit der Anlage von Städten begonnen, und die Barbaren selbst passten sich den neuen Sitten an, gewöhnten sich an Märkte und trafen sich zu friedlichen Zusammenkünften. "16 Diese verstärkte Provinzialisierung des militärisch und politisch durchdrungenen Raumes setzte offensichtlich bereits vor dem Beginn der großen Aufstandsbewegung 1 n. Chr. ${ }^{17}$ ein, die Tiberius in den Jahren 4-5 n. Chr. endgültig niederwarf, die militärischen Strukturen reorganisierte und die Durchringung des Landes vollendete. Mit dem großen Zangenangriff auf das MarbodReich mit Kern in Böhmen im Jahre 6 n. Chr. sollte dann der letzte germanische Machtfaktor beseitigt und die römische Kontrolle bis zur Sudeten/Beskiden-Linie, dem Herkynischen Wald, errichtet werden, ein Unternehmen, das dann aber kurz vor dem endgültigen Erfolg wegen des Aufstandes in Pannonien und Dalmatien abgebrochen werden musste. ${ }^{18}$

${ }^{14}$ Vgl. B. Rudnick, Die römischen Töpfereien von Haltern (Mainz 2001).

15 Tacitus, Annales 1.59.6.

${ }^{16}$ Cassius Dio 56.18.2. Vgl. die Beiträge in Römische Städte nördlich der Alpen. Die Stadt - Instrument der Okkupation und der Herrschaftssicherung, Jb. Heimat- und Altertumsverein Heidenheim 8 (1999/2000), 7-119; von Schnurbein 2002, a.a.O. (Anm. 11).

17 Velleius Paterculus 2.104.2.

${ }^{18} \mathrm{Zu}$ den historischen Vorgängen in Germanien zusammenfassend R. Wolters, Römische Eroberung und Herrschaftsorganisation in Gallien und Germanien (Bochum 1990); dens., Die Römer in Germanien (München ${ }^{4}$ 2004); D. Timpe, $R G A^{2} 11$ (1998), 210-225; Eck 2004, a.a.O. (Anm. 7), 63ff.; mehrfach problematisch M. Gechter, ,Die Militärgeschichte am Niederrhein von Caesar bis Tiberius - eine Skizze', in Grünewald und Seibel 2003, a.a.O. (Anm. 5), 145-161. 
Der Aufstand 1-4/5 n. Chr. hat den Ausbau der Provinzorganisation zweifellos gehemmt, dieser wurde dann aber unter der Statthalterschaft des P. Quinctilius Varus seit $6 \mathrm{n}$. Chr. gezielt vorangetrieben. ${ }^{19}$ Die Errichtung von städtisch strukturierten Mittelpunktssiedlungen zielte auf die Erschließung des Raumes, auf die Konzentration der Eliten in den Zentralorten, auf die Einrichtung von Strukturen der Selbstverwaltung und damit auf die Beherrschbarmachung des Raumes. Man sollte deshalb nicht von einer Urbanisierungspolitik in Sinne von Städtegründungen um der Verbreitung städtischer Siedlungsweise willen sprechen; Zentralorte als Mittelpunkte von politisch-organisatorischen Einheiten in den Provinzen waren als tragende untere Ebene für das administrative Funktionieren des Reiches, das ja über keine eigene Administration im eigentlichen Sinne verfügte, unverzichtbar. Entsprechend hatte Pompeius Bithynien und Pontus in Stadtterritorien organisiert oder Augustus das 25-24 v. Chr. annektierte kleinasiatische Reich des Amyntas, um nur diese Beispiele zu nennen. Die Dynamik der einsetzenden römischen Durchdringung zeigt sich auch in der Tatsache, dass im Sauerland bereits in großem Stil mit der Ausbeutung der Bleivorkommen begonnen wurde. ${ }^{20}$

Bereits während des zweiten Aufenthaltes des Agrippa in Gallien 20-19 v. Chr. und nach dem Abschluß der Eroberung der iberischen Halbinsel hatte der Bau der strategischen Hauptstraßen von der zentralen der Rhône-Achse und dem Straßenknotenpunkt Lugdunum, dem neuen römischen Zentrum Galliens, über die Saône-Achse zum Oberrhein und über die Moselachse zum Mittelrhein (Niederrheinische Bucht), wo der Großverband der Sugambrer als Hauptgegner erschien, ${ }^{21}$ begonnen. ${ }^{22}$ Wohl bereits 15/14 v. Chr., jedenfalls aber mit dem Jahre 13 v. Chr. setzte die Errichtung einer Reihe von zentralen militärischen

${ }^{19}$ Vgl. auch Cassius Dio 56.18.2-3.

${ }^{20}$ Vgl. E. Riccardi und S. Genovesi, ,Un carico di piombo da Rena Maiore (Aglientu), in Africa Romana 14, 2 (Sassari 2002), 1311-1321; P. Rothenhöfer, ,Geschäfte in Germanien. Zur Ausbeutung von Erzlagerstätten unter Augustus in Germanien', ZPE 143 (2003), 277-286; Eck 2004, a.a.O (Anm. 7), $75 f$.

${ }^{21}$ Vgl. D. Timpe, ,Die Rheingrenze zwischen Caesar und Drusus', in Monumentum Chiloniense. Studien zur augusteischen Zeit. Festschr. E. Burck (Amsterdam 1975), 124-147.

${ }^{22}$ Vgl. Strabo 4.6.11. Die weiteren strategischen Straßen führten von Ludgunum nach Aquitanien und zur Kanalküste bzw. verbanden Lyon mit der westlichen Narbonensis und Massilia. Das Straßennetz im Süden bis Lyon muß aber bereits in den Jahren vor 20 v. Chr. ausgebaut worden sein, da sonst die Entwicklung Lyons nicht zu erklären wäre und zudem hier strategische Logistik für die Spanischen Kriege geschaffen werden mußte. 
Basisräumen und -stellungen entlang des linken Rheinufers ein, die zum einen die Endpunkte der logistischen Nachschublinien ins innere Galliens und zum Mittelmeer hin darstellten und andererseits den Endpunkten der durch die naturräumliche Gliederung gegebenen Verkehrslinien im freien Germanien gegenüberlagen. Es waren dies Mainz für die Mainlinie, Koblenz für die Lahnlinie, Bonn für die Sieg- und Aggerlinie, Neuß am Ende für die Wupper- und Ruhrlinie (Hellweg/Bergisches Land) mit der direkten Gegenstellung von Moers-Asberg, Vetera/ Xanten, der Ausgangspunkt für die Drususfeldzüge 12/11 v. Chr., für die zentrale Lippelinie und Nijmegen für das Rheinmündungsgebiet, das Berkel- und Issel-Gebiet sowie Gelderland. Sie waren damit zugleich die Ausgangsbasen für die römischen Operationen östlich des Rheins, die sich auf diese vorgegebenen Kommunikationslinien zu stützen hatten, wie auch die militärische Deckung für die Wege ins innere Galliens (Mainz: Nahe/Glan/Pfälzer Pforte/Oberrheintal, Koblenz: Mosel, Bonn/Köln: Ahr/Eifelstraße/Niederrheinische Bucht, Neuß: Erft-Linie, Xanten: Niederrheinisches Tiefland/Maas-Gebiet, Nijmegen: Maas-Gebiet). ${ }^{23}$ Erst nach dem römischen Rückzug nach der Varus-Niederlage 9 n. Chr. entwickelten sich in diesen Basisräumen festere Standortstrukturen, die nach dem von Tiberius angeordneten Abbruch der offensiven Germanienpolitik 16-17 n. Chr. zur Etablierung fester Armeegarnisonen entlang der Rheinlinie führten; jeweils zwei Legionen lagen den Hauptwegen in das freie Germanien und aus ihm heraus gegenüber, und zwar in Mainz und Vetera, in Neuß waren es schwankend 1-2 Legionen. Die zu Zentralgallien hin offene südliche obergermanische Rheinfront wurde nun durch Legionsgarnisonen in Straßburg und Vindonissa gedeckt. Der Rhein war in vorrömischer Zeit keine Scheidelinie gewesen. Die Rheinzone und der Strom waren in ihrer wirtschaftlichen Bedeutung eher marginal. Die wichtigen Handelswege verliefen über den Rhein hinweg (Salz, Eisen, Buntmetall, Sklaven). Der Strom gewann erst durch den für das römische Militär und die römische Wirtschaft charakteristischen Massengütertransport seine große Bedeutung als zentrale Kommunikationslinie.

Die Phase nach der caesarischen Eroberung war durch eine minimale römische Einflussnahme in die inneren Angelegenheiten der gallischen

${ }^{23}$ Vgl. K. Strobel, ,Die Legionen des Augustus. Probleme der römischen Heeresgeschichte nach dem Ende des Bürgerkrieges', in Limes XVIII. Proceedings of the XVIIIth International Congress of Roman Frontier Studies (Oxford 2002), 51-66. 
Civitates geprägt gewesen, wie auch die Intensivierung der einheimischen Prägetätigkeit gerade in der Gallia Belgica, und hier insbesondere für die Treverer, zeigt. ${ }^{24}$ Römische Münzen bestimmen das Bild des Münzumlaufs außerhalb der Militärzone und -basen erst in tiberischer Zeit. ${ }^{25}$ Die Treverergebiete waren zum einen in den innergallischen Handel und dessen Verknüpfung mit dem Mittelmeerraum integriert, wie beispielsweise die Verbreitung der Dressel 1-Amphoren oder der Münzen des anepigraphen Silberhorizontes des Marberger Typs zeigt, auf der anderen Seite kann das Treverergebiet fast als der westlichste Teil jenes Geflechts wirtschaftlicher und kultureller Beziehungen gelten, das sich über den Mittelgebirgsraum nach Franken, Böhmen und in den Donauraum erstreckte. ${ }^{26}$ Gleiches zeigt die Münzprägung der Treverer, ${ }^{27}$ welche in Gold und Potin Vorbilder der westlichen Nachbarn aufgriff (Ostgallien, Belgica), und deren anepigrapher Silberhorizont typologisch zu der Gruppe der mittel- und süddeutschen Quinare gehörte, deren Zone sich bis nach Böhmen erstreckt und der süddeutschen OppidaKultur zuzurechnen ist. ${ }^{28}$

Während Divodurum, das römische Metz bereits das vorrömische Stammeszentrum und Oppidum der Mediomatriker gewesen war, hatte die keltische Civitas der Treverer oder besser der große Volksverband der Treverer ${ }^{29}$ keinen entsprechenden Zentralort. Die Treverer zerfie-

${ }^{24}$ Vgl. C. Haselgrove, 'The significance of the Roman conquest for indigeneous monetary economies in northern Gaul and southern Britain', in K. Strobel, Hg., Forschungen zur Monetarisierung und ökonomischen Funktionalisierung von Geld in den nordwestlichen Provinzen des Imperium Romanum (Trier 2004), 27-52; R. Loscheider, ,Fremd oder einheimisch - ein Wechselspiel von Einflüssen?', ebd. 159-179; D.G. Wigg, 'The development of the monetary economy in north Gaul in the late La Tène and early Roman period', in J. Creighton und R. Wilson, Hgg., Roman Germany: Studies in Cultural interaction (Oxford 1999), 99-124.

${ }^{25} \mathrm{Vgl}$. auch D.G. Wigg, ,Das Ende der keltischen Münzgeldwirtschaft am Mittelrhein', Germania 61 (1998), 377-397.

${ }^{26}$ Vgl. etwa A. Müller-Karpe, ,Grab 1445. Ein keltischer Streitwagenkrieger des 3. Jh. v. Chr.', in A. Haffner, Hg., Gräber-Spiegel des Lebens. Zum Totenbrauchtum der Kelten und Römer am Beispiel des Treverer-Gräberfeldes Wederath-Belginum (Mainz 1989), 141-160, bes. Karte a.a.O. 157.

${ }_{27}$ Vgl. Haselgrove 2004, a.a.O. (Anm. 24); Loscheider 2004, a.a.O. (Anm. 24); dens., ,Untersuchungen zum spätlatènezeitlichen Münzwesen des Trevererlandes ${ }^{6}$, Archaeologia Mosellana 3 (1998), 61-225.

${ }^{28}$ Vgl. D.G. Wigg und J. Riederer, ,Die Chronologie der keltischen Münzprägung am Mittelrhein', in U. Peters, Hg., Stephanos Nomismatikos. Festschrift E. Schönert-Geis (Berlin 1998), 661-674.

${ }^{29}$ Vgl. zur Geschichte der Treverer zusammenfassend H. Heinen, Trier und das Trevererland in römischer Zeit (Trier 1985), 1-66; auch F. Schön, DNP 12/1 (2002), 
len offenkundig in mehrere weitestgehend selbständige Teilstämme, wie wir dies mehrfach in der politischen Struktur der keltischen Völkerschaften finden; als Beispiel möchte ich hier nur auf die in jeweils vier Teilstämme unter je eigener politischer, jurisdiktioneller und militärischer Führung zerfallenden Großstämme der kleinasiatischen Galater, der Tolistobogier, Tektosagen und Trokmer, hinweisen, deren gemeinsame Bundesversammlung primär der Bereinigung von Konflikten zwischen den 12 Teilverbänden diente, die sich nur in Ausnahmesituationen eine gemeinsame Führung gaben. ${ }^{30}$ Caesar schildert Vergleichbares für die gallischen Civitates. ${ }^{31}$ Die regionale Gliederung der treverischen Teilverbände spiegelt sich in den spätlatènezeitlichen Oppida, ${ }^{32}$ welche die Mittelpunkte der jeweiligen Teilverbände bildeten: Donnersberg, ${ }^{33}$ dessen Rolle später vermindert auf Otzenhausen überging, Martberg, ${ }^{34}$

787-791; ferner C.M. Ternes, Hg., Les secteurs ruraux de la civitas Treverorum. Recherches récentes (1975-1987), BAL 18, 1987 (Luxemburg 1988).

${ }^{30} \mathrm{Vgl}$. K. Strobel, ,Die Staatenbildung bei den kleinasiatischen Galatern', in H. Blum u. a., Hgg., Brückenland Anatolien (Tübingen 2002), 231-293, bes. $238 f f$.

31 Caesar, De bello Gallico 6.23.5: „Im Frieden gibt es keine gemeinsame Leitung der Civitas, sondern die Häuptlinge der Bezirke und Pagi (principes regionum atque pagorum) sprechen unter ihren Leuten Recht und bereinigen die Streitigkeiten."

32 Vgl. auch D. Krauße und O. Nakoinz, ,Binnenkolonisation und Zentralisation. Überlegungen zur latènezeitlichen Besiedlungs- und Bevölkerungsentwicklung im Mittelgebirgsraum nördlich der Mosel', in Les processus d'urbanisation à l'âge du Fer (Glux-en-Glenne 2000), 127-140; S. Rieckhoff in S. Rieckhoff und J. Biel, Die Kelten in Deutschland (Stuttgart 2001), 254-256; H. Nortmann, ,Die eisenzeitlichen Burgwälle im Trierer Land', in A. Haffner und A. Miron, Hgg., Studien zur Eisenzeit in HunsrückEifel-Raum (Trier 1991), 121-140.

33 Vgl. H. Bernhard, in Rieckhoff-Biel 2001, a.a.O. (Anm. 8), 320-323; zur Region insgesamt G. Lenz-Bernhard und H. Bernhard, ,Das Oberrheingebiet zwischen Caesars gallischem Krieg und der flavischen Okkupation (58 v.-73 n. Chr.). Eine siedlungsgeschichtliche Studie', Mitteilungen des Historischen Vereins der Pfalz 89 (1991), 1-347. Mit einer Fläche von 240ha und einer Länge der Umwallung von 8,5km bildete das Oppidum auf dem Donnersberg eine der größten latènezeitlichen Stadtanlagen überhaupt. Es handelte sich bei dem Donnersberg-Oppidum um den Zentralort der nördlichen Pfalz und Rheinhessens, dessen Bedeutung durch seine Münzprägung unterstrichen wird. Die Aufgabe des Oppidums erfolgte ebenso wie diejenige der spätlatènezeitlichen Flachsiedlungen der östlichen Pfalz (Mutterstadt-Horizont) früh in LtD2 vermutlich noch in vorcaesarischer Zeit.

34 Vgl. H.-H. Wegner, ,Der Martberg bei Pommern an der Mosel', Archaeologie an Mittelrhein und Mosel 12 (Koblenz 1997); dens., in Rieckhoff-Biel 2001, a.a.O. (Anm. 8), 445-448; D.G. Wigg, ,Der Beitrag des Martberg zur eisenzeitlichen Numismatik', in Haffner-Schnurbein 2000, a.a.O. (Anm. 2), 485-496; M. Thoma, ,Der gallo-römische Kultbezirk auf dem Martberg bei Pommern an der Mosel (Kreis Cochem-Zell)', ebd. 447-483; D.G. Wigg-Wolf, Hg., Koblenz: Der Martberg bei Pommern (ehem. Kreis Cochem) I, FMRD IV 4, 1 (Mainz 2005). 
Kastel an der Saar, ${ }^{35}$ Wallendorf an der Sauer, das spätestens um die Mitte des 1. Jh. v. Chr. aufgegeben wurde ${ }^{36}$ und Titelberg. Die relativ starke wirtschaftliche Orientierung des Treverergebietes in vorcaesarischer Zeit nach Osten und Südosten spiegelt auch die Verbreitung treverischer Prägungen. ${ }^{37}$

Die Zentralortsfunktion im nordwestlichen Treverergebiet war nach den Aufgabe von Wallendorf vollständig an das 43 ha umfassende Oppidum auf dem Titelberg übergegangen, das zwischen 50 und $30 \mathrm{v}$. Chr. die dominierende Stellung in der Civitas der Treverer innehatte. ${ }^{38}$ Sein Auf- und Ausbau erfolgte in der 1. Hälfte des 1.Jh. v. Chr. Der Ort war durch seine verkehrsgeographische Lage ausgezeichnet, da sich hier die traditionelle Verkehrsverbindung aus Südgallien in Richtung zum Rhein und in die Champagne verzweigte. Der öffentliche Platz und das Heiligtum sowie die zentrale Stellung in der treverischen Münzprägung nach Mitte des 1. Jh. v. Chr. weisen die Zentralortsfunktion des Ortes aus. Der Aufstand der Treverer 30-29 v. Chr. führte zur Eroberung des Platzes durch römische Truppen mit einem Brandzerstörungshorizont und zur anschließenden Präsenz römischen Militärs. ${ }^{39}$ Die wieder aufgebaute Siedlung war jedoch nur mehr von geminderter Bedeutung und

35 Vgl. H. Nortmann, in Rieckhoff-Biel 2001, a.a.O. (Anm. 8), 388-390.

36 Vgl. S. Rieckhoff, in Rieckhoff-Biel 2001, a.a.O. (Anm. 8), 254f.; D. Krauße ebd. 483f.; dens., ,Der ,Kasselt‘ bei Wallendorf (Kr. Bitburg-Prüm). Befestigung, Siedlung und Heiligtum keltisch-römischer Zeit', Trierer Zeitschrift 59 (1996), 17-78; dens., Zur Entwicklung eines regionalen Siedlungszentrums von der Frühlatènezeit bis in spätrömische Zeit. Ausgrabungsergebnisse in Wallendorf, Kr. Bitburg-Prüm‘, in HaffnerSchnurbein 2000, a.a.O. (Anm. 2), 7-21; dens., ,Die Genese eines gallo-römischen Heiligtums im Zentrum eines aufgelassenen Oppidums', ebd. 383-396.

37 Vgl. die Verbreitungskarten bei Loscheider 1998, a.a.O. (Anm. 27), bes. 80f., 82-84; auch die Verbreitung der Potin-Münzen des Typs mit den struppigen Haaren/ Eber ebd. 102f.

${ }^{38}$ J. Metzler, Das treverische Oppidum auf dem Titelberg. Zur Kontinuität zwischen der spätkeltischen und frührömischen Zeit in Nordgallien, 2 Bde. (Luxemburg 1995); dens, ,Vorbericht zu den Ausgrabungen im keltisch-römischen Heiligtum auf dem Titelberg 6 , in HaffnerSchnurbein 2000, a.a.O. (Anm. 2), 431-445; dens., ,Fouilles du sanctuaire celtique et gallo-romain de l'oppidum du Titelberg', in M. Reddé u.a., Hgg., La naissance de la ville dans l'antiquité (Paris 2003), 263-269; dens.und C. Gaeng, ,Camp militaire romain ou établissement de commerçants italiques dans l'oppidum du Titelberg?', Bulletin Musée national d'histoire et d'art Luxembourg 17 (2004), 36-37; N. Metzler-Zens, Lamadelaine, une nécropole de l'oppidum du Titelberg (Luxemburg 1999); J. Kaurin, ,Oppidum du Titelberg: la nécropole orientale', Bulletin Musée national d'histoire et d'art Luxembourg 17 (2004), 38-39; F. Schön, DNP 12/1 (2002), 626f.

${ }^{39}$ Es ist m. E. eine unrichtige Fragestellung: Präsenz römischen Militärs oder italischer Händler. Beides ging immer Hand in Hand. Nach der Niederschlagung der Aufstandbewegung in der Belgica und insbesondere im Treverergebiet ist mit einer verstärkten direkten Kontrolle durch römisches Militär ohne Zweifel zu rechnen. 
entwickelte sich zu einem 10-15 ha großen römischen Vicus, dessen Heiligtum die Kulttradition fortführte. Die römische Seite hat nach 29 v. Chr. ganz offenkundig die zentrale Stellung des Titelberges, die sie ohne Zweifel zuerst bewusst gefördert hatte, beseitigt und die Civitas wieder in zahlreiche Pagi, kleinere regionale Organisationseinheiten, aufgespaltet. In römischer Zeit fassen wir in der Civitas der Treverer, die allerdings gegenüber der mittleren Spätlatènezeit das Gebiet der Untermosel (Martberg-Oppidum) und große Teile der südöstlichen Gebiete mit dem zentralen Donnersberg-Oppidum eingebüßt hatte, inschriftlich bisher fünf Pagi ${ }^{40}$ die nun natürlich Teil der römischen verwaltungsrechtlichen Organisation der Civitas waren.

Der Titelberg selbst war verkehrsmäßig ungünstig gelegen, nachdem sich die Kommunikationslinien, insbesondere das römische Hauptstraßennetz sowie militärische Versorgung und wirtschaftliche Dynamik auf die Moselachse und zum Rhein hin ausrichteten (Wasserweg der Mosel, Eifelstraße, Moselstraße). Auch die Leistungsanforderungen an die gallischen Civitates für die Versorgung des römischen Heeres richteten sich auf die Rheingarnisonen und damit auf die dorthin führenden Transportwege aus. ${ }^{41}$ Seit dem Ende des 1. Jh. v. Chr. war für die gesamte Civitas Treverorum eine neue verkehrsmäßige, abgabenmäßige und wirtschaftliche Orientierung gegeben, in welcher der Titelberg, der nun abseits der Hauptstraßen Reims-Trier und LyonMetz-Trier-Köln/Andernach/Mainz lag, seine überregionale Bedeutung verlieren musste. An seine Stelle trat als Straßenknotenpunkt der Vicus Orolaunum/Arlon, ${ }^{42}$ der auch als Pagus-Vorort fungierte. Die wichtige vorrömische Verkehrsachse, welche die Oppida Donnersberg, Otzenhausen, Kastel und Titelberg verbunden und die Mosel bereits auf einer festen Brücke überschritten hatte ${ }^{43}$ sowie über den Titelberg weiter ins Remergebiet führte, fand keine direkte Nachfolge. Wie auch die Münzspektren zeigen, war das westliche und mittlere Treverergebiet vorrangig nach Westen orientiert gewesen. Der Bedeutungsverlust des Titelberges spiegelt sich auch in dem Verschwinden repräsentativer

${ }^{40}$ Vgl. Heinen 1985, a.a.O. (Anm. 29), 104ff.; Zum Verhältnis von Civitas und Pagus bzw. Zentralort vgl. etwa S. Rieckhoff, in Rieckhoff-Biel 2001, a.a.O. (Anm. 8), 250f.; U. Nonn, $R G A^{2} 10$ (1998), 471-473; 22 (2003), 449f.; H. Galsterer, DNP 9 (2000), 146f.

${ }^{41}$ Vgl. etwa Tacitus, Annales 1.71.2; 2.5.3; 2.6 .1 zu den Jahren 15 und 16 n. Chr.

${ }^{42}$ Vgl. F. Schön, DNP 9 (2000), 49.

${ }_{43}$ Moselübergang von Stadtbredimus-Palzem; Dendrodaten der Hölzer 140 und 122 v. Chr. 
Baustrukturen im Heiligtumsbereich um ca. 20 v. Chr., an deren Stelle dann erst wieder Mitte des 1. Jh. n. Chr. Kultbauten traten. Das relativ dichte vorrömische Wegenetz zwischen den Oppida und innerhalb der Stammesgebiete wurde durch das römische Straßennetz abgelöst, das mehrfach zu Neustrukturierungen innerhalb der gallischen Civitates führte. ${ }^{44}$ Es ist mehrfach zu beobachten, dass die Zentralorte der gallischen Civitates entsprechend von den Plätzen der Oppida an die Straßen und Straßenkreuzungen verlegt wurden.

Wir können mit gutem Grund im Titelberg ein Zentrum des romfreundlichen Teils des treverischen Adels sehen, an dessen Spitze während des gallischen Krieges Cingetorix stand, der mit seinem Schwiegervater Indutiomarus um die Vorherrschaft im Verband der treverischen Teilstämme und ihrer Bundesversammlung rivalisierte und von Caesar 53 v. Chr. für seine Treue mit der höchsten politischen und militärischen Führungsposition, principatus atque imperium, in der Civitas belohnt wurde. ${ }^{45} 51$ v. Chr. kam es nochmals zu einer Erhebung von gallischen Stämmen unter Beteiligung von Teilen der Treverer, die Zuzug rechtrheinischer Verbündeter erhielten; im Jahre 50 führte Caesar eine Machtdemonstration in Form einer große Heeresparade im Land der Treverer durch, um die Ruhe zu garantieren. ${ }^{46}$ Charakteristisch für die Politik Caesars ist es, dass es zu keiner Beseitigung der gallischen Aristokratie kam, sondern diese vielmehr ihre Macht über Land und Leute behielt. Nur die Gegner der caesarischen Politik wurden ausgeschaltet bzw. liquidiert. ,Ganz Gallien` hatte er zur Provinz gemacht, „mit Ausnahme der verbündeten und um Rom verdienten Civitates. ${ }^{647}$ Sie blieben formal unabhängige Staatsgebilde, die mit Rom durch völkerrechtliche Vertragsverhältnisse als foederati bzw. amici et socii verbunden waren und damit einen privilegierten Status unter der römischen Herrschaft innehatten, der sie natürlich ebenso untergeordnet waren wie die tributpflichtigen Stammesstaaten (civitates stipendiariae). Dies gilt natürlich auch für die Treverer, die in ihrer privilegierten Stellung wohl 30-29 v. Chr. von einer civitas libera et foederata zu einer civitas foederata herabgestuft worden waren. ${ }^{48}$

\footnotetext{
${ }^{44}$ Vgl. auch Heinen a.a.O. 1985, (Anm. 29), 26.

${ }^{45}$ Caesar, De bello Gallico 5.3-4; 5.57.2; 6.8.9.

6 Caesar, De bello Gallico 8.45; 8.52.1.

47 Sueton, Julius 25.1.

48 Plinius, Naturalis Historia 4.106; vgl. hierzu auch Heinen 1985, a.a.O. (Anm. 29), 60 .
} 
Kommen wir nun zur Frage der Gründung des neuen Hauptortes der Treverer. ${ }^{49}$ Bereits aus dem Namen Augusta Treverorum, ,AugustusStadt der Treverer, ist zu Recht auf die gezielte Gründung Triers als Hauptstadt der Civitas in augusteischer Zeit zu schließen, wobei schon für die Namensgebung eine Genehmigung durch den Princeps vorgelegen haben muß. ${ }^{50}$ Als Terminus ante quem für die Gründung des Hauptortes und eines entsprechenden Handelns der Civitas als Körperschaft bzw. ihrer Repräsentanten an diesem Ort kann das Memorialmonument für die Enkel des Augustus Gaius (+ 4 n. Chr.) und Lucius Caesar (+ 2 n. Chr.) gelten. ${ }^{51} \mathrm{Als}$ wahrscheinlicher Gründungstag der Stadt kann der 1.8. eines unbekannten Jahres erschlossen werden, wobei zu Recht auf die Bedeutung dieses Tages als Tag der Weihe des Roma et Augustus-Altars für die gallischen Provinzen in Lugdunum $\mathrm{zu}$ verweisen ist. ${ }^{52}$ An diesem Tag versammelten sich nun jährlich die Vertreter der gallischen Civitates, um ihre Loyalität zu bekunden. Wie K.P. Goethert überzeugend darlegen konnte, ist die Orientierung des Decumanus der Stadt von der Groma der Neugründung aus auf den Sonnenaufgang an den Äquinoktien ausgerichtet, also auf den Geburtstag des Augustus am 23. September. ${ }^{53}$ Hierin werden der ideologische Hintergrund und die Beziehung auf Person und Kult des Augustus besonders fassbar. Bereits das älteste Straßennetz war für eine geplante städtische Siedlung nach römischem Muster ausgelegt; die Lehmfachwerkbauten der ältesten Phase wurden nach kurzer

${ }^{49}$ Vgl. hierzu H. Heinen 1985, a.a.O. (Anm. 29), 41ff.; K.-J. Gilles, ,Neue Funde und Beobachtungen zu den Anfängen Triers', Trierer Zeitschrift 55 (1992), 193-232; P. Hoffmann, ,Die Stadtentwicklung am römischen Forum in Trier ${ }^{6}$, Funde und Ausgrabungen in Bezirk Trier 30 (1998), 53-68; H. Löhr, ,Drei Landschaftsbilder zur Natur- und Kulturgeschichte der Trierer Talweite‘, ebd. 7-28; H.-P. Kuhnen, ,Die Anfänge des römischen Trier. Alte und neue Forschungsansätze', in Precht 2001, a.a.O. (Anm. 5), 143-156; K.P. Goethert, ,Untersuchungen zum Gründungsschema des Stadtplans der Colonia Augusta Treverorum. Die Geburt der Stadt an der Mosel', Archäologisches Korrespondenzblatt 33 (2003), 239-257. Zum römischen Trier weiter E.M. Wightman, Roman Trier and the Treveri (London 1970); Trier. Augustusstadt der Treverer (Mainz $\left.{ }^{2} 1984\right)$, bes. H. Löhr 7ff.; A. Haffner 16ff.; K.-J. Gilles 20ff.; H. Cüppers 48ff.; H.-P. Kuhnen, Das römische Trier (Darmstadt 2001): geht im Historischen nicht über H. Heinen hinaus; ferner H. Cüppers, in Die Römer in Rheinland-Pfalz (Stuttgart 1990), 577-647, 647f. (Ehrang); F. Schön, DNP 2 (1997), 285-290.

50 Vgl. Heinen 1985, a.a.O. (Anm. 29), 43, 46-53.

51 Vgl. Heinen 1985, a.a.O. (Anm. 29), $47 \mathrm{ff}$.

52 Vgl. Heinen 1985, a.a.O. (Anm. 29), 46f. Goethert 2003, a.a.O. (Anm. 49), 249f. stellt dies in Frage und plädiert für den 23.9., den Geburtstag des Augustus, als Gründungstag; seine Darlegungen sind jedoch keineswegs zwingend.

${ }^{53}$ Goethert 2003, a.a.O. (Anm. 49). 
Zeit durch Steinbauten ersetzt. ${ }^{54}$ Das erste Straßensystem, das in der Bundsandsteinschotterung der Straßenkörper fassbar wird, wurde symmetrisch und planmäßig nach den Grundsätzen antiker Stadtplanung und Proportionslehre angelegt. ${ }^{55}$ An der Kreuzung von Cardo und Decumanus befand sich das erste, kleinere Forum, das eine Fläche von vier rechteckigen Insulae einnahm. Beiderseits des Decumanus, der vom Straßenraster weg mit zwei leichten Knicken zur Moselbrücke führte, lagen westlich und östlich des Forums jeweils zwei rechteckige Insulae. Nördlich und südlich schlossen sich daran beiderseits des Decumanus jeweils $3 \times 3$ Insulae an. In flavischer Zeit wurde der Forumsbereich zu seiner späteren Größe erweitert. Die Verteilung des zeitlich dem Oberaden-Horizont (11-8 v. Chr.) zuzuordnenden Materials zeigt die rasche und flächige Besiedlung dieser Gründungsphase, deren erste Erweiterung bereits in den Haltern-Horizont (bis 9 n. Chr.) fällt; in tiberischer Zeit ist die Siedlung bereits über das ursprüngliche Straßenraster hinausgewachsen, das dann in flavischer Zeit im Sinne des regulären Insula-Rasters erweitert wurde. ${ }^{56}$ Das erste, ohne Zweifel von Spezialisten aus dem Ingenieurkorps des Heeres entworfene und vermessene Straßennetz erstreckte sich zwar auf hochwasserfreie Terrassenbildungen, erforderte jedoch die Nivellierung von Geländestufen und griff im Süden bereits auf den Schwemmfächer des Altbaches sowie im Nordosten auf eine Feuchtsenke aus. ${ }^{57}$ Das Gelände war somit keineswegs ideal für eine Stadtanlage. Zudem grenzte es im Norden an ein Altwasser und einen Altarm der Mosel, ein Gelände, das bei der Erweiterung des Stadtgebietes erst durch Aufschüttungen und aufwendige Grundierungen hergerichtet werden musste.

Die Talweite der Mosel bei Trier stellt einen verkehrsmäßig zentra-

${ }^{54}$ Vgl. Cüppers 1990, a.a.O. (Anm. 49); Löhr 1998, a.a.O. (Anm. 49); Goethert 2003, a.a.O. (Anm. 49).

${ }^{55}$ Vgl. hierzu jetzt Goethert 2003, a.a.O. (Anm. 49) mit Korrektur der von Löhr vorgelegten Ergebnisse.

${ }_{56}$ Vgl. zusammenfassend Goethert 2003, a.a.O. (Anm. 49), 248, 250. Die Beiträge von Kuhnen 2001, a.a.O. (Anm. 49) führen in der Frage der Stadtgründung nicht über das Bekannte hinaus.

57 Vgl. H. Löhr, ,Drei Landschaftsbilder zur Natur- und Kulturgeschichte der Trierer Talweite', Funde und Ausgrabungen im Bezirk Trier 30 (1998), 7-28; dens., ,Intensivierte Bodenerosion als Folge römischer Landnutzung in der Trierer Talweite und in ihrem Umfeld', in Haffner-Schnurbein 2000, a.a.O. (Anm. 2), 175-199; dens., ,Die Mosel. Aspekte der naturgeschichtlichen Entwicklung des Trierer Mosellaufes und seiner Archäologie', in H.-P. Kuhnen, Hg., Abgetaucht. Aufgetaucht. Flußfundstïcke (Trier 2001), 67-86; die Ergebnisse des Teilprojekts 10 Umweltgeschichte der Region Trier des SFB 522 (Universität Trier). 
len Raum für das gesamte Treverergebietes dar. ${ }^{58}$ Durch die Zuflüsse von Saar, Biewerbach, Altbach und Ruwer sowie der Kyll, an deren Linie sich der Eifel nach Norden anbot, sind wichtige Verkehrszugänge gegeben, während gleichzeitig mehrere traditionelle Moselübergänge vorhanden waren, so eine jedenfalls seit dem 2. Jh. v. Chr. benutzte Furt im heutigen Stadtgebiet. Hier kreuzte sich die vorgeschichtliche Süd-Nord-Verbindung durch Hunsrück und Eifel mit der Verkehrslinie entlang von Mosel und Saar. Die Trierer Talweite weist jedoch keine größere vorrömische Siedlung auf. Nur am Altbach bestand eine bis in die Frühlatènezeit zurückreichende kleinere Siedlung. Die Süd-NordVerbindung gewann erst in römischer Zeit ihre große Bedeutung. Die Wichtigkeit des Kylltales wird durch die beiden latènezeitlichen Burganlagen und Adelssitze von Ehrang und Kordel unterstrichen. In der vorcaesarischen Münzverteilung scheint östlich der Kyll eine gewisse Regionalgrenze gewesen zu sein. Offensichtlich ist der Raum um die Trierer Talweite einerseits teils als Randzone des Trevererverbandes zu sehen, dessen Mittelpunkt das Oppidum von Wallendorf bildete, zum anderen teils als Randzone des Verbandes mit Zentrum im Oppidum von Kastel. Östlich der Kyll begann vermutlich der Einflussbereich des Oppidums auf dem Martberg. Die Trierer Talweite war zwar verkehrsmäßig bedeutsam, befand sich aber offensichtlich in der politischen Gliederung des Großverbandes der Treverer in einer inneren Randständigkeit. Hinzu kommt, dass erhebliche Teile der Niederung Auen-, Überschwemmungs- und Feuchtgebiete waren.

30-29 v. Chr. hatte M. Nonius Gallus den Aufstand der Treverer, die Unterstützung von rechtsrheinischen Stämmen (,Germanen'), erhalten hatten, niedergeschlagen. ${ }^{59}$ Gegen die Moriner und weitere aufständische Civitates der Belgica war gleichzeitig C. Carrinas erfolgreich vorgegangen und hatte außerdem einen Übergang, suebischer' Gruppen über den Rhein zurückgeschlagen. ${ }^{60}$ Carrinas operierte offenkundig in der nördlichen Belgica. Mit den Operationen des Nonius Gallus ist zum einen die Zerstörungsschicht des Jahres 30 v. Chr. im Oppidum Titelberg zu verbinden wie auch die Errichtung des großen Militärlagers

${ }^{58}$ Vgl. zur geographischen Lage und zur geschichtlichen Entwicklung bis $30 \mathrm{v}$. Chr. H. Löhr, in Trier. Augustusstadt der Treverer (Mainz $\left.{ }^{2} 1984\right), 9-15$; A. Haffner ebd. 16-19.

${ }^{59}$ Cassius Dio 51.20.5; vgl. PIR ${ }^{2} \mathrm{~N} 137$.

${ }^{60}$ Cassius Dio 51.21.6; vgl. $P I R^{2}$ C 447. 
auf dem Petrisberg oberhalb des späteren Stadtgebietes von Trier ${ }^{61}$ von dem aus die gesamte Talweite der Mosel von der Mündung der Saar bis zur Mündung der Kyll überblickt und alle wichtigen Verkehrswege im Innern der Civitas mit Ausnahme ihrer Verbindungen im Westen kontrolliert werden konnten. Die Dendrodaten für das Fälldatum der erhaltenen Hölzer weisen den Baubeginn des Lagers in das Frühjahr $30 \mathrm{v}$. Chr. Das Lager auf dem Petrisberg war durch zwei Befestigungsgräben, die quer über den Bergrücken laufen, von der Hochfläche abgeriegelt und war mit einer Fläche von mindestens $250 \times 600 \mathrm{~m}$, in der Mannschaftsbaracken, Versorgungsgebäude und Pferdeställe trotz der starken neuzeitlichen Störungen im Befund erscheinen, für die Aufnahme eines größeren Korps, wohl einer starken Legionsvexillation und Auxiliarreiterei, geeignet. Zu dem Lager gehörte mit Sicherheit auch ein Flusshafen für die Versorgung auf dem Wasserwege. Das Lager war nur eine relativ kurze Zeit belegt und dürfte spätestens im Zusammenhang der Truppenbewegungen 15/12 v. Chr. in seiner Besatzung verringert und schließlich aufgelassen worden sein. Allerdings ist m.E. mit einer ausreichenden militärischen Sicherung des überaus wichtigen Nachschubknotenpunktes und der Moselbrücke bis 8 v. Chr., dem Beginn der Einrichtung der Provinz Germania, zu rechnen. ${ }^{62}$ Mit dem Lager auf dem Petrisberg und der sehr wahrscheinlichen Präsenz römischen Militärs auf dem Titelberg haben wir wohl nur einen Teil der römischen Truppenstandorte zur Kontrolle der Treverer und insbesondere zur Unterbindung einer Zusammenarbeit mit rechtsrheinischen Kräften vor uns. ${ }^{63}$ Eine entsprechende Truppenpräsenz ist insbesondere

${ }^{61} \mathrm{Zu}$ den aktuellen Ausgrabungen vgl. die Berichte in Funde und Ausgrabungen im Bezirk Trier 34 (2002); 35 (2003); 36 (2004); P. Dietze u.a., Der Petrisberg in Trier (Trier 22004).

${ }^{62}$ Das in der Forschung mehrfach postulierte römische Militärlager im Südteil der Stadt ist nicht existent; hier kam es zu einer Fehlinterpretation von neuzeitlichen Befestigungsstrukturen; vgl. Goethert 2003, a.a.O. (Anm. 49), 251-253.

${ }^{63}$ Vgl. auch Heinen 1985, a.a.O. (Anm. 29), 40; S. Fichtl, ,La présence militaire romaine sur les oppida dans la Gaule du nord et de l'est', in Studien zur Archäologie der Kelten, Römer und Germanen in Mittel- und Westeuropa. Festschrift A. Haffner (Rahden/Westfalen 1998), 153-168, bes. 164ff. Ein neu entdecktes spätlatènezeitliches Oppidum von 18ha Fläche liegt auf dem Hochplateau des Bleidenberges bei Oberfell an der unteren Mosel; es erscheint nach seiner Größe dem Martberg-Oppidum eindeutig untergeordnet, hatte aber durch seine Beherrschung des Koblenzer Raumes ohne Zweifel eine große Bedeutung. Nach einer frühlatènezeitlichen Belegung wurde das Oppidum im späten 2. Jh. v. Chr. Mit einem 2,5 km langen, zweiphasigen Wall befestigt. Seine Hauptphase fällt in das 1. Jh. v. Chr. und erstreckt sich noch in die Zeit nach der römischen Okkupation. Wie beim Martberg-Oppidum, zu dessen Befestigungsanlagen deutliche Parallelen bestehen, ist auch hier mit einer Aufgabe nach dem Trevereraufstand 30-29 v. 
an der Untermosel und im Bereich der Mündung des Flusses, also im Raum von Koblenz, zu erwarten.

Das älteste sichere Zeugnis aus dem Trierer Stadtgebiet ist der Bau der Moselbrücke; die Hölzer für diese Pfahlrostbrücke wurden 18 und 17 v. Chr. gefällt. Der Bau der festen Moselbrücke steht ohne Zweifel mit dem von Agrippa 20-19 v. Chr. eingeleiteten Straßenbau in Gallien in einem direkten Zusammenhang. Die von Lugdunum/ Lyon zum Rhein gebaute Straße hat von Metz kommend sicherlich das Militärlager auf dem Petrisberg angebunden und zu dessen Füßen die Mosel nach Norden überschritten, um dann auf der Linie über Bitburg die Eifel zu durchqueren und die Erft zu erreichen. Die erste Moselbrücke ist in ihrer Lage eindeutig auf einen Zugang zum Lager auf dem Petrisberg über dessen Nordwestflanke ausgerichtet. Die Ausrichtung der Insula-Bebauung weicht von dieser Straßenrichtung deutlich ab und muß deshalb sekundär entstanden sein. Außerdem führte die nach Norden führende Moselstraße schräg durch das Insula-Raster der Stadterweiterung zum Beginn des ursprünglichen Cardo. Der ursprüngliche Verlauf der Straße führte offenbar auf der Terrassenstufe direkt zur Moselbrücke. Auch die von Konz kommende römische Hauptstraße mündete mit einer leichten Abweichung in den ursprünglichen Cardo. Die Straßen gingen somit der Einrichtung des Straßennetzes der Stadtgründung voraus. Die Bedeutung dieses Straßenbaus ${ }^{64}$ für die Neustrukturierung des treverischen Raumes wird auch in der frühen planmäßigen Gründung des römischen Etappenortes Dalheim wahrscheinlich um 10 v. Chr. anstelle einer kleinen spätlatènzeitlichen Vorgängersiedlung, zu der aber offenbar keine direkte Kontinuität bestand, deutlich. ${ }^{65}$ Während die erste Trasse der römischen Hauptstraße Metz-Trier-Rheinische Bucht östlich der Mosel geführt wurde und die Saar bei Konz überschritt, ist offenkundig bereits nach 15 bzw. um 10 v. Chr. die Trasse westlich des Flusses gebaut worden, die vor der Sauermündung in die wichtige Straße Reims - Trier-Andernach/ Koblenz mündete, die sicher ebenfalls in dieser Zeit angelegt wurde und

Chr. zu rechnen. Vgl. G. Brücken, ,Ein neues keltisches Oppidum an der unteren Mosel bei Oberfell, Kreis Mayen-Koblenz,' Archäologie in Rheinland-Pfalz (2002), 45-47.

${ }^{64}$ Vgl. auch Heinen 1985, a.a.O. (Anm. 29), 107ff., $121 \mathrm{ff}$.

${ }^{65}$ Vgl. J. Krier, ,Zu den Anfängen der römischen Besiedlung auf dem Petzel bei Dalheim', in Publications de la Section Hististorique Institut Grand-Ducal de Luxembourg 94 (1980), 141-194; dens., ,Das vorrömische und frührömische Dalheim (Luxemburg)', in Trier. Augustusstadt der Treverer (Mainz ${ }^{2}$ 1984), 79-86; dens., ,Neue Zeugnisse der Götterverehrung aus dem römischen Vicus Dalheim', Hémecht 44 (1992), 55-82. Das Fundmaterial setzt mit dem Oberaden-Horizont ein. 
sich unmittelbar am nördlichen Brückenkopf der Trierer Moselbrücke mit Straße Metz-Trier-Köln kreuzte. Die Strecke Reims-Arlon-Trier besaß ohne Frage eine herausragende logistische Bedeutung für die Versorgung der Rheinarmee aus dem Inneren Galliens heraus.

Die zentrale Bedeutung von Trier für die Logistik der römischen Heere am Rhein, sowohl des unteren wie den oberen Heeres, wird dadurch dokumentiert, dass sich der Sitz des kaiserlichen Finanzprokurators der Gallia Belgica und beider Germanien, der für das Finanzwesen der Rheinheere zuständig war und zugleich an der Organisation ihrer Logistik wesentlich beteiligt war, in Trier befand. ${ }^{66}$ Es erscheint durchaus möglich, eine entsprechende administrative Stelle für die Verwaltung der zum Rhein geführten Versorgungsgüter bereits seit 15 v. Chr. auf dem Petrisberg anzunehmen. Die Finanzverwaltung der Gallia Belgica für das an ihrer Ostflanke aufmarschierte Heer war jedenfalls schon während des Census 13-12 v. Chr. zu organisieren. Damit kommen wir aber zu der problematischen Frage des Gründungsdatums der Stadt Trier. H. Heinen hat sich mit gewichtigen Gründen für einen Gründungsakt vor 12 v. Chr., dem Zeitpunkt des Abschlusses der endgültigen Organisation der gallischen Provinzen ausgesprochen. ${ }^{67}$ Ohne Zweifel handelte es sich, wie Heinen oder Goethert betonen, um eine bewusste, auf römischen Prinzipien der Stadtanlage basierende Neugründung, nicht um eine allmähliche Stadtwerdung. Es lag also ein entsprechender Gründungsakt der Civitas mit Zustimmung der römischen Autorität oder vielmehr wohl auf deren Anordnung hin zugrunde. Beide Forscher favorisieren das Gründungsjahr 17 v. Chr., ohne dass es hierfür aber wirkliche Argumente gibt. ${ }^{68}$ Das Straßennetz wurde planmäßig und in einem Zug angelegt, zweifellos mit Unterstützung der römischen Administration und der Spezialisten und Arbeitskolonnen des römischen Heeres. Der Ort der Gründung wurde, wie wir mit gutem Grund betonen können, von römischer Seite unterhalb des Truppenlagers

${ }^{66}$ Vgl. zuletzt R. Haensch, Capita Provinciarum (Mainz 1997), 74, 130-133.

${ }^{67}$ Vgl. Heinen 1985, a.a.O. (Anm. 29), 45f., 50ff.

${ }^{68}$ Goethert 2003, a.a.O. (Anm. 49), bes. 249f. (23.9.17 v. Chr.). Weder die Datierung des Baus der Moselbrücke noch der Verweis auf die Ludi Saeculares des Jahres 17 v. Chr. sind tragfähige Argumente. Die Ausrichtung auf den Geburtstag des Herrschers und damit auf die Person des Augustus, dessen Namen die Stadt tragen sollte, war ein politisch-ideologischer Akt der römischen Führung. Dieser Tag braucht aber nicht der Gründungstag der Stadt zu sein. Die inschriftlichen Werkdaten von der Porta Nigra, einem Bau der Stadtbefestigung unter Beteiligung des römischen Heeres, können nicht als Beleg gegen den 1.8., der nur für die städtische Führungsschicht ein Feiertag war, herangezogen werden. 
auf dem Petrisberg festgelegt. Die gesamte Trierer Talweite und die Höhen um den Petrisberg waren ohne Zweifel bei der Anlage des Lagers beschlagnahmt und der direkten Militäradministration unterstellt worden. Das Gebiet in der Niederung musste also von römischer Seite ausdrücklich für die Gründung der Stadt an die Civitas Treverorum zurückgegeben werden, um hier deren ,Augustusstadt ${ }^{‘}$ überhaupt errichten zu können. Es spricht alles dafür, dass diese Neuorganisation der Civitas Treverorum, welche die Gründung eines Civitashauptortes unter römischer Anleitung und Unterstützung beinhaltete, mit dem Census des Drusus den Älteren im Jahre 13 v. Chr. in Zusammenhang steht. Es ist durchaus denkbar, dass der Gründungsakt nach den entsprechenden Vorarbeiten am gleichen Tag wie die Weihung der Ara Galliarum in Lyon, also am 1.8.12 v. Chr. erfolgt ist. Die organisatorische Ordnung des ostgallischen Raumes war eine wichtige Voraussetzung für jede offensive Strategie am Rhein. Mit der Umgruppierung des römischen Heeres seit 15 v. Chr. trat die Schaffung der logistischen Infrastruktur für die Konzentration der römischen Kräfte am Rhein und für Operationen über diesen hinaus nach Osten in den Mittelpunkt. Die bisherige dezentrale Organisation der Civitas Treverorum war für die Erfassung und Verfügbarmachung ihrer Ressourcen für die Versorgung der römischen Armeen nicht geeignet. Vielmehr war die Schaffung einer zentralen Institution als Adressaten der römischen Leistungsanforderungen erforderlich, d. h. ein Gemeinderat mit leitenden Funktionären für die gesamte Civitas. ${ }^{69}$ Eine zentral strukturierte Selbstverwaltung der Civitates mit klar verantwortlichen Gremien und Leitungspersonal war für das administrative System des Reiches geradezu unverzichtbar. Auch war ein zentraler Punkt für Stapelung, Transport und Administration der Versorgungsgüter an diesem Straßenknoten, der zugleich eine Schnittstelle mit der für den Massengütertransport so wichtigen Wasserstraße der Mosel war, im Grunde eine gebotene Lösung. Die unbehinderte Heranziehung der Ressourcen der Civitates und hier insbesondere auch der Treverer war ein wesentliches Ziel der römischen Politik. ${ }^{70}$ Durch die Gründung des neuen Hauptortes

\footnotetext{
${ }^{69}$ Bei der Beendigung des sogenannten Bataveraufstandes flüchteten 70 n. Chr. 113 treverische Ratsherren (senatores), also offenbar der gesamte Gemeinderat in das Gebiet jenseits der Reichsgrenze; Tacitus, Historiae 5.19.4.

${ }^{70}$ Vgl. die Klage der aufständischen Treverer in der Erhebung des Iulius Florus und des Iulius Sacrovir $21 \mathrm{n}$. Chr. über die continuatio tributorum, die Fortdauer der Abgaben für die formal in einem Foederatenverhältnis mit Rom stehende Civitas (Tacitus, Annales 3.40.4).
} 
auf ,neutralem Grund‘ konnten Rivalitäten zwischen den treverischen Teilverbänden vermieden werden, und die römische Führung hat vermutlich aufgrund der bisherigen Erfahrungen mit der durchaus schwierigen, in sich völlig zerstrittenen Adelselite der Treverer, die sich $21 \mathrm{n}$. Chr. im Aufstand des Iulius Florus, dessen Familie bereits von Caesar das Bürgerrecht erhalten hatte, ${ }^{71}$ nochmals bestätigen sollten, ${ }^{72}$ bewusst an keinen der bisherigen Zentralorte angeknüpft. Die Anlage auf diesem für die Errichtung einer Stadtanlage nicht besonders geeigneten, aber durch die von Rom für das Heer geschaffenen Verkehrsstrukturen so zentralen Gelände kann nur als eine römische Entscheidung gewertet werden, die der Civitas Treverorum so vorgegeben wurde. Der Ort war auf die römische Moselbrücke, den Flusshafen und die römische Herrschaftspräsenz bezogen. Mit der Heeresversorgung sowie dem weiteren Bedarf und der Kaufkraft der Soldaten war zugleich aber auch eine wirtschaftliche Grundlage ${ }^{73}$ für die Stadtgründung geschaffen, die sich aus der römischen Neustrukturierung des ostgallischen Raumes und der römischen Militärpolitik ergab. Die Rechtsstellung der Civitas und ebenso jene ihres Hauptortes blieb peregrin, zumindest bis in claudische Zeit; ${ }^{74}$ die Bezeichnung der Stadt als Colonia bei Tacitus in der Schilderung der Ereignisse 69-70 n. Chr. kann aber nicht als ,untypische Verwendung' des Begriffes abgetan werden, sondern zeigt eine Veränderung des Status vor diesem Zeitpunkt an, und zwar die Erhebung zur Colonia latinischen Rechts. Trier war wahrscheinlich eine der letzten Städte überhaupt, die in diesen Status erhoben wurden. Weder eine Usurpation des Colonia-Titels noch eine Verleihung ehrenhalber ohne jede rechtliche Folgen sind als Alternativen wirklich denkbar. Die fragmentarische Inschrift AE 1968, 321 aus Mainz nennt den absteigenden Cursus eines vornehmen Treverers aus iulisch-claudischer bis flavischer Zeit. ${ }^{75}$ Er war Priester des provinzialen Kaiserkultes in Lyon, hatte zuvor ein Amt der Colonia Treverorum inne und war

\footnotetext{
71 Tacitus, Annales 3.40.1.

72 Tacitus, Annales 3.40-42.

${ }^{73}$ Zur wirtschaftlichen Orientierung des Treverergebietes vgl. auch Heinen 1985, a.a.O. (Anm. 29), $141 \mathrm{ff}$.

${ }_{74}$ Vgl. überzeugend Heinen 1985, a.a.O. (Anm. 29), 60-66, 392.

${ }^{75}$ J. Krier, Die Treverer außerhalb ihrer Civitas (Trier 1981), 92-96 Nr. 33; vgl. Heinen 1985, a.a.O. (Anm. 29), 61ff. Das Cognomen Tiber[ianus] kann eine Namensgebung im Sinne einer Loyalitätsbekundung kurz nach dem Florus-Sacrovir-Aufstand $21 \mathrm{n}$. Chr. bedeuten. Alle vorgeschlagenen Ergänzungen der Inschrift sind mit Ausnahme der Nennung des Priesteramtes an der Ara Galliarum und der Präfektur des Rheinufers unsicher.
} 
als ritterlicher Offizier Praefectus ad ripam Rheni gewesen. Die in Z. 6 und 7 genannten Laufbahnstationen sind unsicher; dagegen kann in Z. 7 begründet [in civita]te Treve[rorum]/[-] ergänzt werden, so dass ich für Z. 6/7 vorschlagen möchte: [-Jrum qua[aestori $I I^{76} /$ in civita]te Treve[rorum]. Aus der Inschrift ergibt sich entgegen den bisherigen Annahmen aber keineswegs, dass Trier als Colonia latinischen Rechts und die peregrine Civitas der Treverer nebeneinander existiert hätten. Vielmehr kann sich die Laufbahn gerade über den Zeitpunkt der Statusveränderung der Civitas Treverorum hinweg erstreckt haben.

Mit der Gründung Triers hatte die römische Führung einen entscheidenden Beitrag zur Ausbildung des historischen Raumes an der Mosel geleistet, wobei die Motive weniger in einer oft zitierten Urbanisierungspolitik lagen, sondern vielmehr in der administrativen Neuorganisation des ostgallischen Raumes mit einer militärischen und logistischen Zielsetzung. Die Ausbildung dieses ostgallischen Zentralortes sollte insbesondere im späteren 3. Jh. n. Chr. respektive in der Spätantike ${ }^{77}$ und im Mittelalter ihre volle Bedeutung entfalten und im besten Sinne raumbildend wirken. Als Partner in Produktion, Handel, Transport und Geschäftsfinanzierung der militärischen Stellen und der Administration in der Organisation der Heeresversorgung entwickelte sich eine 'business class,' die wir in ihren Inschriften und Grabmonumenten von der Rhone bis zur Mosel und zum Rhein, insbesondere in Lyon und im Raum von Trier, fassen können.

Mogontiacum ${ }^{78}$ das römische Mainz, nimmt wiederum eine eigene Sonderstellung unter den städtischen Siedlungen der Rheinzone ein. Die Errichtung der großen Militärbasis auf dem Hochplateau des Kästrich und einer zugehörigen Hafenbasis am Strom ist ohne Zweifel

${ }^{76}$ Alternativ wären quaestori r(ei) p(ublicae) oder quaestori p(ecuniae) p(ublicae) denkbar.

77 Vgl. H. Heinen, Frühchristliches Trier (Trier 1996).

78 Vgl. J. Oldenstein, RGA 20 (2002), 144-153; R. Klein, Hg., Die Römer und ihr Erbe. Fortschritt durch Innovation und Integration (Mainz 2003), bes. L. Schumacher, ,Mogontiacum. Garnison und Zivilsiedlung im Rahmen der Reichsgeschichte', ebd. 1-28; R. Haensch, ,Mogontiacum als ,Hauptstadt‘ der Provinz Germania Superior', ebd. 71-86; O. Höckmann, ,Mainz als römische Hafenstadt', ebd. 87-105; ferner Haensch 1997, a.a.O. (Anm. 66), 149-153; M. Witteyer, ,Mogontiacum-Militärbasis und Verwaltungszentrum. Der archäologische Befund', in Mainz. Die Geschichte der Stadt (Mainz 1998), 1021-1058; dies., ,Zur römischen Besiedlung von Mainz-Weisenau', in Provinzialrömische Forschungen. Festschrift G.Ulbert (Espelkamp 1995), 273-288; U. Ehmig, Die römischen Amphoren aus Mainz, 2 Bde. (Möhnesee 2003). Der Beitrag von G. Ziethen, ,Mogontiacum. Vom Legionslager zur Provinzhauptstadt', in Mainz. Die Geschichte der Stadt (Mainz 1998), 39-70 ist in jeder Beziehung enttäuschend. 
mit dem Beginn der Offensive des Drusus in Germanien zu verbinden und ab 13-12 v. Chr. anzusetzen; spätestens 10 v. Chr. war hier die Hauptbasis der südlichen Rheinfront mit einer Garnisonsstärke von zwei Legionen und Auxilien ausgebaut. Ein Dendrodatum von 17-16 v. Chr. könnte auf einen etwas früheren Beginn römischer Präsenz am Ort unmittelbar vor oder nach der Clades Lolliana hinweisen. Die HolzErde-Mauer des Doppellegionslagers wurde bereits in augusteischer Zeit mehrfach ausgebessert und dann in tiberischer Zeit völlig erneuert. Wie die neuen dendrochronologischen Daten für die Pfahlrostgründung der Pfeiler der ersten festen Rheinbrücke zeigen, wurde diese in den Jahren 25-27 n. Chr. errichtet. ${ }^{79}$ Um das Lager entwickelte sich zuerst vor der Südwestfront die Lagersiedlung, die canabae legionis. Eine relativ lockere Bebauung dehnte sich dann bis zum Rhein hin aus, wobei das Gelände vielfach durch Aufschüttungen hergerichtet werden mußte. Im Bereich der ausgedehnten Hafenanlagen entstand im Gebiet des sogen. Dimesser Ortes die erste eigentliche Zivilsiedlung beim dortigen großen Frachthafen. Das Praetorium des obergermanischen Legaten bzw. Militärgouverneur und dann ab 85 n. Chr. des Provinzstatthalters lag nicht im Legionslager auf dem Kästrich, ${ }^{80}$ sondern im Bereich zwischen Lager und Rhein, wobei m.E. wie in Köln wohl mit einer Nähe zum Fluß und zum Hafenbereich ,Brand' (Kriegshafen) sowie zur direkten Fortsetzung der Via Praetoria anzunehmen ist. Neben dem großen Frachthafen im Bereich Dimesser Ort war in der Achse der Via Praetoria des Lagers auf dem Kästrich etwas stromaufwärts der römischen Rheinbrücke der Kriegshafen des 1. und 2. Jh. n. Chr. sowie der Spätantike angelegt und noch etwas weiter stromaufwärts ein zweiter, wohl primär militärischer Frachthafen, wo auch eine Werft aus augusteischer Zeit gefunden wurde; die Kaianlagen wanderten mit der Verlandung des Ufers und der Verlagerung des Flusslaufes nach Osten bzw. Nordosten. ${ }^{81}$

Frühe militärische Brückenköpfe waren in Mainz-Kastel und gegenüber von Mainz-Weisenau errichtet worden. In dem rechtsrheinischen

${ }^{79}$ Vgl. S. Bauer, in: www.roemisches-mainz.de/mainz/inhalt/fundberichte.html. dies., ,Recycling in römischer Zeit: Spundbohlen einer frührömischen Brückenkonstruktion als Uferrandbefestigung in der Mainzer Holzstraße', Archäologie in Rheinland-Pfalz (2003), 35-38.

${ }^{80}$ Vgl. entsprechend AE 1964, 148: das Praetorium „ad hiberna leg(ionis) XXII $P$ (rimigeniae) p(iae) f(idelis).“

${ }^{81}$ Vgl. Höckmann 2003, a.a.O. (Anm. 78) mit Abb. 3. 
Vorfeld von Mainz, das vor Mitte des 1. Jh. v. Chr. unter der Kontrolle des Heidetränk-Oppidums gestanden hatte, wurden vermutlich um die Zeitenwende oder aber bereits im Rahmen der Politik des Tiberius 8 v. Chr. die Mattiaker, ${ }^{82}$ offensichtlich ein Teilverband der Chatten in einem engen Vertragsverhältnis zu Rom, angesiedelt und als Civitas organisiert; dies steht wohl mit der Neuordnung des chattischen Raumes, der in Waldgirmes einen städtischen Civitasvorort bekommen sollte, in direktem Zusammenhang. Als Vorort der Mattiaker wurde der augusteisch gegründete Vicus Mattiacum bzw. Aquae Mattiacae nahe den bereits in der 1. Hälfte des 1. Jh. n. Chr. bekannten Thermalquellen errichtet. ${ }^{83}$ Die Parallele zu der Gründung der Civitasvororte am Niederrhein (Oppidum Batavorum, Oppidum Cugernorum) in der Nähe großer römischer Militärbasen ist sicher nicht zufällig.

Für die römische Militärplanung war die Gründung der Militärbasis durch die strategische Lage gegenüber der Mainmündung geradezu vorgegeben. Mainz lag hier am Ende bzw. Anfang eines der wichtigsten Verkehrswege aus dem und in das Innere Germaniens, wobei sich traditionelle Flußübergänge ober- und unterhalb der Mainmündung, die sich in entsprechenden vorgeschichtlichen Flußfunden spiegeln, befanden. Ebenso kontrollierte das wohl nur wenig nach $13-12$ v. Chr. 3,5 km rheinaufwärts auf der Hochfläche errichtete zweite Militärlager MainzWeisenau einen alten Flußübergang. Das Lager von Mainz-Weisenau, für das nur völlig unzureichende Erkenntnisse vorhanden sind, war offensichtlich eine Bereitstellungsbasis für weitere Truppen neben dem Doppellegionslager und hatte dementsprechend bis in domitianische Zeit wechselnde Garnisonsstärken und wohl auch Lagergrößen.

Nach Süden und Südwesten dehnt sich das Hügelland Rheinhessens aus, dessen Plateau hier mit einem Steilabfall zu den Uferterrassen des Rheins abfällt, wobei sich das Flußufer gegenüber der römischen Zeit schrittweise nach Osten bzw. Nordosten verschoben hat. ${ }^{84}$ Der Raum vom Mainz hatte vor der Gründung der römischen Militärbasis keinerlei Mittelpunktsfunktion. ${ }^{85}$ Er war vielmehr in der Grenzzone zwischen dem südöstlichen, vom Donnersberg-Oppidum dominierten

${ }^{82}$ Vgl. zu ihnen R. Wiegels, DNP 7 (1999), $1035 f$.

83 Vgl. zum römischen Wiesbaden A. Becker, $R G A^{2} 19$ (2001), 440-443; W. Czysz, Wiesbaden in der Römerzeit (Stuttgart 1994), 52ff.

${ }^{84}$ Vgl. die Karten bei Höckmann 2003, a.a.O (Anm. 78).

85 Vgl. zur Vorgeschichte des Mainzer Raumes K.V. Decker, ,Die Anfänge der Mainzer Geschichte‘, in Mainz. Die Geschichte der Stadt (Mainz 1998), 1-35. 
Teil der Treverer und dem Einzugsbereich des jenseits des Rheins das Rhein-Main-Gebiet dominierenden Heidetränk-Oppidums bei Oberursel-Oberstedten ${ }^{86}$ gelegen. Das Oppidum mit einer Fläche von 130 ha ist durch seine Bedeutung als Münzprägestätte und durch seine Handwerksquartiere hervorgehoben, in denen eine arbeitsteilige Wirtschaftsweise vom Rohmaterial bis zum Fertigprodukt nachgewiesen werden konnte. In Bad Nauheim befand sich eine unbefestigte latènezeitliche Siedlung, deren Salinen zu den bedeutendsten Orten für Salzgewinnung im keltischen Raum gehörten und zweifellos durch die geradezu vorindustrielle Salzgewinnung vom 3. bis ins 1. Jh. v. Chr. eine Quelle des Reichtums der Region waren. ${ }^{87}$ Südlich des Mains finden sich bis zum Rand des Odenwalds zahlreiche offene latènezeitliche Siedlungen, eine Ringwallanlage fehlt jedoch in diesem Raum, so dass mit einer Zugehörigkeit zum Stammesverband um das HeidetränkOppidum zu rechen sein dürfte. Die Aufgabe des Heidetränk-Oppidums ist wahrscheinlich nicht ganz eine Generation vor jener des DünsbergOppidums im Lahntal, ${ }^{88}$ also nicht lange nach 50 v. Chr. anzusetzen;

${ }^{86}$ Vgl. F. Maier, $R G A^{2} 14$ (1999), 157f.; dens., in Rieckhoff-Biel 2001, a.a.O. (Anm. 8), 438-441; dens., Das keltische Heidetränk-Oppidum bei Oberursel im Taunus. Archäologische Denkmäler in Hessen 10 (Wiesbaden ${ }^{2}$ 1993). Der Ausbau der beiden älteren latènezeitlichen Befestigungen Altenhöfe und Goldgrube zu einem großen Oppidum erfolgte in der 2. Hälfte des 2. Jh. v. Chr. Vgl. insgesamt A. Jockenhövel, in F.-R. Herrmann und A. Jockenhövel, Hgg., Die Vorgeschichte Hessens (Stuttgart 1990), 244ff., bes. $270 \mathrm{ff} ., 461 \mathrm{f}$.

${ }_{87} \mathrm{Vgl}$. B. Kull, Hg., Sole und Salz schreiben Geschichte. 50 fahre Landesarchäologie, 150 Fahre archäologische Forschungen in Bad Nauheim (Mainz 2003).

${ }_{88}$ Vgl. C. Schlott, Zum Ende des spätlatènezeitlichen Oppidums auf dem Dünsberg (Gem. Biebertal-Fellingshausen, Kreis Gießen, Hessen). Forschungen zum Dünsberg 2 (Montagnac 1999); K. Reeh, Der Dünsberg und seine Umgebung. Eine Bestandsaufnahme. Forschungen zum Dünsberg 1 (Montagnac 2001); J. Schulze-Forster, Die latènezeitlichen Funde vom Dünsberg (Diss. Marburg 2002); K.-F. Rittershofer und J. Schulze-Forster, ,Forschungen am Dünsberg I-II', Berichte der Kommission Archäologische Landesforschung Hessen 6 (2000/2001), 125-146; K.F. Rittershofer, Ausgrabungen 1999 bis 2003 am keltischen Oppidum auf dem Dünsberg bei Gießen, Berichte der Römisch-Germanischen Kommission 85 (2004), 7-36; Grabungsberichte in www.duensberg.de; www.archaeologie-online. de/magazin/fundpunkt/2004/09/duensberg_1.phb; 2005/04/duensberg_3.phb. Vgl. auch Roymans 2004, a.a.O. (Anm. 6), bes. 130, 148. Die keltischen und römischen Waffenfunde insbesondere im Bereich vor Tor 4 und auch Tor 5, die bisher oft mit einem Kampfgeschehen des Drususfeldzuges 10 v. Chr. verbunden wurden, erweisen sich als Teil kultischer Deponierungen. Eine gewisse Präsenz römischen Militärs auf dem Dünsberg, der nur 8 km von der Stadtgründung Waldgirmes entfernt ist und das gesamte Wetzlar-Gießener Becken sowie die Butzbacher Taunussenke beherrscht, kann m. E. zu Recht vermutet werden. Das offensichtlich nur kurzzeitig wohl in den Jahren 10-8 v. Chr. belegte Lager von Dorlar, das etwa eineinhalb Legionen Platz geboten hat, liegt zwischen Waldgirmes und dem Dünsberg, steht jedoch kaum mit einer postulierten römischen Eroberung des Dünsbergs in Beziehung. Das späte Fundgut des 
die Existenz des Dünsberg-Oppidums, des ursprünglichen Zentralortes des batavisch-chattischen Verbandes, dessen Bedeutung offensichtlich seit ca. 50-40 v. Chr. bereits abgenommen hatte, reicht dagegen noch bis in die Zeit ca. 30/vor 20 v. Chr. (Ende des hessischen Latène D 2).

Die vorgeschichtlichen Siedlungen lagen auf der linksrheinischen Hochterrasse oder an deren Rand; auch die rechtsrheinische Uferzone war siedlungsleer. In der Latènezeit geht die Zahl der Siedlungsstellen im Mainzer Raum gegenüber der Urnenfelder- und Hallstattzeit stark zurück. In der ausgehenden Latènezeit ist nur die keltische Siedlung in Mainz-Bretzenheim und die spätestkeltische Siedlung in MainzWeisenau zu erwähnen; letztere entstand wohl erst nach 30-29 v. Chr. und wurde von dem dort angelegten Militärlager und der etwa gleichzeitig entstandenen Zivilsiedlung überbaut, die einheimische Bevölkerung ging in den neuen Siedlungsstrukturen auf. Hier können wir sehr wahrscheinlich die äußerste Randzone treverischer Siedlungen in der 2. Hälfte des 1. Jh. v. Chr. in Rheinhessen fassen; die Siedlungen und das zentrale Mars Loucetius-Heiligtum von Klein-Winternheim/ Ober-Olm ${ }^{89}$ sind mit dem wohl treverischen Teilverband der Aresaces zu verbinden. Bereits unter römischer Herrschaft, vielleicht in Verbindung mit der Neuordnung nach 30-29 v. Chr., nahm die keltische Besiedlung mit Gehöften im Raum bis zur Nahe und einer größeren Siedlung in Alzey wieder zu. Dagegen können wir im Raum Bad Kreuznach spätkeltisch-römische Siedlungskontinuität fassen. ${ }^{90}$

Im Gegensatz zu anderen großen Legionslagern wurde die Zivilstadt des römischen Mainz nie in den Status einer autonomen Stadtgemeinde erhoben. ${ }^{91}$ Die Bewohner bezeichneten sich als Mogontiacenses. ${ }^{92}$ Die zivile Besiedlung, die sich in flavischer Zeit zwischen Kästrich und Rhein städtisch verdichtete, zerfiel in die Canabae Legionis ${ }^{93}$ und eine Reihe

\footnotetext{
Dünsberg zeigt mitteldeutsche-elbgermanische Beeinflussung, die offensichtlich einen entscheidenden Faktor in der chattischen Ethnogenese darstellte.

${ }^{89}$ CIL XIII 7252; vgl. etwa M.J. Klein, in Die Römer und ihr Erbe. Fortschritt durch Innovation und Integration (Mainz 2003), 109.

${ }^{90}$ Vgl. das Gräberfeld von Badenheim; A. Böhme-Schönberger, ,Der keltischrömische Bestattungsplatz von Badenheim', in Des Lichtes beraubt (Wiesbaden 1995), 80-86.

${ }_{91}$ Vgl. auch Schumacher 2003, a.a.O. (Anm. 78), bes. 1, 11; Witteyer 1998, a.a.O. (Anm. 78), 1040f.; ferner Haensch 2003, a.a.O. (Anm. 78).

${ }^{92}$ CIL XIII 11810.

93 Vgl. die Weihung der Mainzer Iupitersäule durch die canabarii (Römische Steindenkmäler. Mainz in Römischer Zeit (Mainz 1988), 90f.).
} 
von Vici ${ }^{94}$ welche die Organisationsebene des zivilen Stadtgebietes bildeten, das ebenso wie das Umland und die Zivilsiedlung von MainzWeisenau stets unter der direkten Verwaltung des Militärgouverneurs bzw. des Statthalters und Kommandeurs der Garnison verblieb. Das Siedlungskonglomerat hatte wohl urbanen Charakter und stellte sich insbesondere seit dem Mauerbau unmittelbar nach 250 n. Chr., der auch die Canabae im Südwesten und Süden des Legionslagers mit einschloß, als eine ummauerte Stadtsiedlung dar, jedoch fehlten die für eine römische Stadt charakteristischen Strukturen und öffentlichen Bauten. Auch liegt der sich von verschiedenen Kernen aus verdichtenden Siedlungsstruktur keine Planung zugrunde und auch später wurden keine Maßnahmen im Sinne einer Stadtplanung ergriffen. Die Achsen des Siedlungsagglomerates waren durch die auf das Legionslager zulaufenden und von dort zu der Rheinbrücke bzw. zum Kriegshafen führenden Straßen bestimmt. Die repräsentativen Bauten standen im Zusammenhang des Heeres: Drusus-Kenotaph, Paradeplatz, Germanicus-Bogen und Bühnentheater im Kontext des Kaiserkultes, der auf dem Memorialkult für Drusus den Älteren aufbaute ${ }^{95}$ ebenso Thermen und Rheinbrücke. Eine eigene Organisation bildete der conventus civium Romanorum (als ,Pseudo-Ordo'), für den im 1. Jh. n. Chr. ein curator civium Romanorum, im 2. Jh. n. Chr. d(ecuriones) c(ivium) $R$ (omanorum M(ogontiacensium) sowie quaestores für die Konventskasse belegt sind.${ }^{96}$ Auch der jüngste Versuch, für Mainz einen städtischen Status zu erweisen, und zwar als Colonia latinischen Rechts, ${ }^{97}$ bleibt

${ }^{94}$ Inschriftlich bezeugt sind der Vicus Appolinensis, Vicus Vobergensis, Vicus Salutaris, Vicus Navaliorum (sicher angrenzend an den militärischen Hafenbereich), Vicus Vic[toriae] und der Vicus Novus; CIL XIII 6722, 6723, 6776, 6688, 6689, 11827.

${ }_{95}$ Vgl. AE 1991, 20, Z. 26-28; Sueton, Claudius 1.3; Cassius Dio 55.2.3; Eutropius 7.13.1; D. Lebek, ,Die Mainzer Ehrungen für Germanicus, den älteren Drusus und Domitian', ZPE 78 (1989), 45-82; dens., ,Ehrenbogen und Prinzentod 9 v. Chr.-23 n. Chr.', ZPE 86 (1991), 47-78. Augustus hatte durch den Senat verfügen lassen, dass jährlich eine Truppenparade durchzuführen war und die gallischen Civitates dem Toten durch eine Supplicatio die Ehre zu erweisen hatten. Der Bogen für Germanicus ist in diesem Ensemble zu suchen; der Bogen in Mainz-Kastel wird heute mit gutem Grund mehrheitlich, wie vom Verfasser schon lange vorgeschlagen, als Siegesmonument Domitians interpretiert.

${ }_{96}$ CIL V 5747; XIII 6676, 6733, 6769, 6775, 7222; Mainzer Zeitschrift 83 (1988), $282 f$.

${ }^{97}$ M.Th. Raepsaet-Charlier, 'Les institutions municipales dans les Germanies sous le Haute-Empire: bilan et questions', in: dies.und M. Dondin-Peyre, Hgg., Cités, municipes, colonies. Les processus de municipalisation en Gaule et en Germanie sous le Haute-Empire 
ohne Grundlage. Die Bezeichnung als civitas auf einer Inschrift diokletianischer Zeit (civitas Mog[ontiac(ensium)]) oder als civitas bzw. municipium durch Ammianus Marcellinus ${ }^{98}$ weisen nur auf die ummauerte Siedlung städtischen Charakters hin, jedoch nicht mehr auf einen spezifischen Rechtsstatus oder eine autonome städtische Organisation. Das römische Mainz blieb bis in die Spätantike durch seine Funktion als zentrale Truppenbasis und als logistisches Zentrum im oberen Abschnitt der Rheingrenze geprägt. Das gesamte Stadtgebiet und sein Umland blieben aufgrund der großen strategischen Bedeutung als solum Caesaris unter direkter kaiserlicher Verwaltung, welche der Militärkommandant und seinen Stab repräsentierten. Handwerk und Handel waren ebenfalls durch den vom Militär geprägten Markt bestimmt.

Die verkehrstechnische Lage von Mainz war hervorragend. Der Platz war durch Kommunikationslinien nach Westen, Südwesten und Süden mit dem gallischen Hinterland und der zentralen Verkehrsachse Lyon-Trier-Köln, ja auf einem fast durchgehenden Wasserweg über Rhône, Saône, Mosel und Rhein mit dem Mittelmeer verbunden. Die Rheintalstraße führte über die Burgundische Pforte ebenfalls nach Lyon. Zugleich lag Mainz am Ende der Mainlinie, der wichtigsten West-OstVerkehrsachse Germaniens. Wäre die Provinzbildung in Germanien erfolgreich verlaufen, so wäre zumindest ein Teil der Mainzer Garnison, wie wir zu Recht annehmen können, auf der Mainlinie nach Osten verschoben worden, wahrscheinlich in das Doppellegionslager von Marktbreit, dessen erste Phase wohl im Zuge der Unternehmungen des Domitius Ahenobarbus in der Frühphase des Haltern-Horizontes wenige Jahre vor der Zeitenwende entstand, das vermutlich unter der Statthalterschaft des M. Vinicius (1-4 n. Chr.) ausgebaut wurde und das 6 n. Chr. zweifellos eine zentrale Rolle bei dem groß angelegten Angriff auf die Markomannen in Böhmen hatte. Das 37 ha große Lager war zwar nie über längere Zeit belegt gewesen,${ }^{99}$ aber dennoch

romain (Paris 1999), 271-352, bes. $311 \mathrm{ff}$. Vgl. allgemein H. Wolff, ,Kriterien für latinische und römische Städte in Gallien und Germanien und die Verfassung gallischer Stammesgemeinden', Bonner Fahrbücher 176 (1976), 45-121.

${ }_{98}$ CIL XIII 6727; Ammianus Marcellinus 15.11.8; 16.2.12.

99 Auffallend ist die Fundarmut des Lagergeländes. Kopfbauten von Mannschaftsbaracken, nicht jedoch diese selbst waren errichtet worden. Dagegen waren Principia, Praetorium, Quaestorium, ein angrenzender Wohnkomplex und Fabricae ausgebaut. Teilweise sind drei Bauphasen festzustellen. Vgl. M. Pietsch, $R G A^{2} 19$ (2001), 329-331; dens., ,Das augusteische Truppenlager Marktbreit', Berichte der Römisch-Germanischen Kommission 71 (1991), 263-324. 
in seinem Ausbau zu einem regulären Legionslager bereits weit fortgeschritten. Vermutlich verhinderte der pannonisch-dalmatische Aufstand die offensichtlich geplante Umgruppierung des oberen Heeres in Germanien. Dass der Raum von Mainz nicht bereits in vorrömischer Zeit angesichts seiner verkehrsmäßigen Lage eine größere Bedeutung entwickelt hat, ist sehr wahrscheinlich durch die oben angesprochene Randlage zwischen zwei latènezeitlichen Großverbänden, jenem der Treverer im Westen und einem namentlich nicht zu benennenden mit Zentrum im Heidetränk-Oppidum begründet gewesen. Der Raum von Mainz konnte auch deshalb nicht diese Bedeutung entfalten, da die keltische Wirtschaftsstruktur markt- und verbrauchsorientierte Transporte von Massengütern sowie einen logistischen Massengüterbedarf nicht kannte. Eine derartige Bevölkerungskonzentration wie in der römischen Militärbasis hatte die keltische Welt nicht gekannt. Erst durch diese neuen Anforderungen und durch die militärische Strategie des römischen Eroberungskrieges konnte sich die Bedeutung von Mainz entsprechend seiner hervorragenden verkehrsgünstigen Lage am Wasserweg von Rhein und Main entfalten und raum- und zentralortsbildend wirken.

Träger und Initiatoren der hier skizzierten Prozesse von herrschaftsbezogener Raumbildung und Raumdurchdringung waren die Entscheidungen der politischen und militärischen Führung des Imperium Romanum; ausführendes Organ war das römische Heer, das nicht nur Kampftruppen, sondern zugleich die Arbeitskolonnen, Facharbeiter und Ingenieure für öffentliche Projekte und Infrastrukturvorhaben stellte. Die den Maßnahmen zugrunde liegenden Ordnungsvorstellungen waren jene der römischen Herrschaft, wie sie sich in der späten Republik herausgebildet hatten und von Augustus in ein zugleich standardisiertes wie flexibel zu handhabendes Grundmuster übergeführt worden sind. Dabei standen zuerst die Strategien der militärischen Herrschaftssicherung und der militärischen Logistik im Vordergrund, dann jedoch auch die Grundstrukturen des notwendigen politisch-administrativen Aufbaus der Gebiete und ihrer Selbstverwaltungseinrichtungen. Durch die Eroberung Galliens war der Rhein seit 54-53 v. Chr. Grenzzone der römischen Herrschaft geworden, obwohl der Fluß in vorrömischer Zeit niemals eine Kultur- oder Völkerscheide dargestellt hatte. Ostgallien war nun die Peripherzone des Imperium Romanum. Durch die Verlegung der römischen Truppen aus dem Inneren Galliens an den Rhein, ihre Verstärkung aus anderen Teilen des Reiches und den Aufbau der großen 
Militärbasen für die offensiven Feldzüge zwischen Rhein und Elbe entwickelte sich hier in kürzester Zeit eine ungeheuere Konzentration von Menschen und Material, von Versorgungsbedarf und Logistik und von Kaufkraft. ${ }^{100}$ Neben den Soldaten der Legionen und Auxilien bildeten sich auch neue Konzentrationen jener Personengruppen, die entweder familiär oder wirtschaftlich mit dem Heer verbunden waren, Händler, Handwerker, Gastronomie, Vergnügungsgewerbe etc. in den zivilen Lagersiedlungen. Es bildeten sich in kurzer Zeit Märkte mit hoher Kaufkraft, die zu Anziehungspunkten des Fernhandels wurden, um die Nachfrage der gut besoldeten Soldaten und Offiziere zu befriedigen. ${ }^{101}$ Auch Handwerksproduktion, die sich auf diese Märkte hin orientierte, entstand im gallischen Hinterland wie in der Militärzone selbst. ${ }^{102}$ Die gesamte Rheinzone hatte derartige demographische und wirtschaftliche Konzentrationen vorher nie gekannt. Mit der Gründung Kölns als künftiger Provinzhauptstadt der im Aufbau befindlichen Provinz Germania hatte die römische Politik die Entstehung eines überregional bedeutenden städtischen Zentrums am Rhein eingeleitet. Doch entscheidend für die weitere Entwicklung sollte die Niederlage des Varus 9 n. Chr. werden, die zum Rückzug auf den Rhein und schließlich in letzter Konsequenz 16-17 n. Chr. zur Aufgabe einer offensiven Germanienpolitik östlich des Rheins führte. Damit waren die großen Militärbasen und die Kette kleinerer Stützpunkte auf dem linken Rheinufer dauerhaft etabliert. Wäre es tatsächlich zur Einrichtung des römischen Germanien zwischen Rhein und Elbe unter Einschluß der östlichen Randzone Galliens und wohl auch Böhmens und Mährens gekommen, so hätte sich der Schwerpunkt des römischen Heeres ebenfalls nach Osten verlagert und vermutlich hätte die Elbe eine zentrale Bedeutung in der infrastrukturellen, wirtschaftlichen und demographischen Entwicklung Europas erlangt. Doch bleibt dies

${ }^{100}$ Vgl. etwa das Beispiel Mainz; Ehmig 2003, a.a.O. (Anm. 78).

101 Vgl. G. Jacobsen, Primitiver Austausch oder freier Markt? Untersuchungen zum Handel in den gallisch-germanischen Provinzen während der römischen Kaiserzeit (St. Katharinen 1995), bes. 139ff.; K. Strobel, Die Ökonomie des Imperium Romanum: Wirtschaftsgeschichte zwischen Primitivismus und Modernismus (Poznán 2004). Allgemein auch H.-J. Drexhage u.a., Die Wirtschaft des Römischen Reiches (1.-3. Jahrhundert) (Berlin 2002).

${ }_{102}$ Vgl. die Beiträge in M. Polfer, Artisanat et production artisanales en milieu rural dans les provinces du nord-ouest de l'Empire romain (Montagnac 1999); Les artisans dans la ville antique (Paris 2002), bes. 77ff.; M. Luik, ,Handwerk in den Vici des Rhein-Maas-Gebietes', in K. Strobel, Hg., Die Ökonomie des Imperium Romanum (St. Katharinen 2002), 169-209. 
natürlich Spekulation. So jedoch blieb das Rheinland die Peripherzone des Imperium Romanum, zugleich eine Militärzone, in der im 1. Jh. n. Chr. rund ein Drittel der gesamten Militärkraft des Reiches konzentriert war. Dieser Peripherraum wurde so zu einem Zentralraum des infrastrukturellen Ausbaus und der wirtschaftlichen Entwicklung, sowohl der regionalen wie der überregionalen, und auch des, internationalen ${ }^{6}$ Fernhandels. Es entstanden Zentralorte, deren Bedeutung das Ende des Imperium Romanum in der Spätantike überlebte und die Entwicklung Europas bis in die Neuzeit prägte (Köln, Mainz, Straßburg, Trier). Vor allem aber war eine Infrastruktur entwickelt worden, welche die Rheinzone zu einer verkehrsmäßigen Zentralzone Europas machte. Dabei zeigt es sich, dass die langfristige Präsenz des Heeres und die Entscheidungen der Reichsadministration für die Entwicklung der Orte, für ihre fortdauernde Bedeutung oder ihren Niedergang, ausschlaggebend waren. Ein gutes Beispiel für die Abhängigkeit der Entfaltung eines städtischen Zentrums vom Florieren der sich dort entwickelnden Militärgesellschaft, jener Gesellschaft aus Soldatenfamilien, Angehörigen von Soldaten und dem vom Militär stimulierten Wirtschaftsleben, ist Neuß, einer der frühesten und wichtigsten römischen Stützpunkte am Rhein, der nach der Auflassung des Legionslagers zu Beginn des 2. Jh. n. Chr. zu einer Straßenstation herabsank. Mainz hätte sicher immer eine zentrale logistische und verkehrsgeographische Schlüsselstellung behalten, so dass sich beim etwaigen Abzug der Legionsgarnisonen vom Rhein nach Osten hier eine Stadt im rechtlichen Sinne und von großer wirtschaftlicher Bedeutung entwickelt hätte, die bei der auch dann zu vermutenden Teilung der Großprovinz Germanien in einen nördlichen und südlichen Sprengel wohl zur Provinzhauptstadt geworden wäre.

Das Heer war der entscheidende Wirtschaftsfaktor in den Provinzen an Rhein und Donau. Die dauerhafte Ausbildung von Zentralität war eine langfristig wirksame Folge der Ausbildung als bleibender Militär- und Grenzzone. Die Bildung dieses langfristig existierenden Peripherraumes des Imperium Romanum im Sinne einer Grenzraumbildung führte zu einer dauerhaften Neustrukturierung des mitteleuropäischen Raumes, wobei die ebenfalls gegebenen langfristigen Wirkungen auf das gallische Binnen- bzw. Hinterland natürlich nicht übersehen werden dürfen, wie das Beispiel Trier zeigt. Die wirtschaftlich und demographisch dynamische Zone verlagerte sich aus dem geographischen Zentralraum Galliens in die nach 16-17 n. Chr. dauerhaft ausgebildete Peripherzone 
des Reiches, zu der gerade auch das ostgallische Trier zu zählen ist, das sich schließlich zu einem überregionalen Oberzentrum und zur kaiserlichen Hauptstadt entfaltete. Durch die römische Herrschaft und das Handeln ihrer Träger kam es zur Ausbildung eines Zentralraumes von bleibender europäischer Dimension, dessen Grundstrukturen alle folgenden Epochen prägen. 